\title{
Technical Advances of Temporary Facilities for the Failure Prevention of Large-Span Cantilever Casting Construction of Mountainous Concrete Box-Type Arch Bridges
}

\author{
HongJu Han $\mathbb{D}^{1},{ }^{1}$ JiPing Guo $\mathbb{D}^{1},{ }^{1}$ JiJin Zhang $\mathbb{D}^{1},{ }^{1}$ and Yuan Sun $\mathbb{D}^{2}$ \\ ${ }^{1}$ Guizhou Road \& Bridge Group Co., Ltd., Guiyang, Guizhou 550001, China \\ ${ }^{2}$ School of Civil Engineering and Mechanics, Huazhong University of Science and Technology, Wuhan, Hubei 430074, China \\ Correspondence should be addressed to Yuan Sun; sunxiao_1981@126.com
}

Received 5 September 2019; Accepted 4 January 2020; Published 6 February 2020

Academic Editor: Raffaele Landolfo

Copyright (C) 2020 HongJu Han et al. This is an open access article distributed under the Creative Commons Attribution License, which permits unrestricted use, distribution, and reproduction in any medium, provided the original work is properly cited.

In the highways of mountainous areas, the erection of the large-span reinforced concrete box-type arch bridges using the cantilever casting method has unique advantages due to its adaptability to those environments. However, what prevents engineers from choosing this design in practice is that, the efficiency, cost, and safety problems resulting from the defects of the temporary facilities, which are due to the span increase, may immediately make the scheme less attractive. To fully consider the merits of this bridge type, new techniques of the temporary facilities are developed. A new form traveler based on the feathers of such arch rings is invented to promote erection efficacy; this new form further facilitates the technical upgrades of the buckle-anchor system monitoring-control and temporary prestressing design, which together eliminate the difficulties brought by the span increase. The inverted-type triangle traveler composed of tiled main truss structures, with the walking hook and anchor tie rod detached, is used to achieve space adaptability, light weight and modularization. The semiautomatic deviation-rectifying system, which combines the technologies of real-time data collection of the buckle pylon deviations and automatic synchronized tensioning, is developed to ensure the safety of the buckle-anchor system. The temporary short prestressed tendons are designed for control of the arch ring tensile stresses. The effectiveness of the technical upgrades has been demonstrated in the construction application of the Shatuo Bridge in Guizhou, China, which provides a promising alternative for the construction of large-span box-type arch rings of concrete arch bridges with a low cost, high efficiency, and high safety assurance.

\section{Introduction}

In mountainous areas, such as in Guizhou, China, the concrete arch bridge is one of the most popular design schemes in highway construction. This is not only due to its superior durability but also because of the environment adaptability of its construction methods [1-3]. Generally, when the arch ring span is lower than $120 \mathrm{~m}$, the scaffolding method [4] and the steel arch frame method are mostly used for such bridges, with few adopting the rotation construction method [5]. For the box-type arch rings with a span greater than $150 \mathrm{~m}[6,7]$, the cantilever casting method utilizing the cable-stayed buckle-anchor to cooperate with the form traveler was theoretically believed to be suitably adapted to the terrain condition, referring to the erection experiences of other large-span bridges [8-10]. However, in Guizhou, only 5 concrete arch bridges have been found within that span range, and only 4 of those use this erection method [11]. Even in China, no more than 10 cases were erected using this method. The main reasons for the scheme being less favorable than we expect in this environment are as follows: (1) the economic advantages of the concrete arch bridges are swallowed up by the cost and low efficiency induced from the traditional form traveler and complex cable-stayed buckle-anchor system [12, 13]; (2) the stress control of the concrete arch ring, in terms of safety and design requirements in the construction procedure, becomes more difficult as the span increases; and (3) the cable-stayed buckle-anchor system may introduce more risks and tedious manipulations because of the larger span [14-16]. 
These difficulties are the result of the temporary facilities' fundamental defects in the traditional cantilever casting method in building the main arch ring, particularly the form traveler. Its structure can facilitate neither working smoothly for high efficiency nor producing a precise arch ring line shape. Since the 1960s, different kinds of form travelers have been invented to build reinforced concrete arch bridges in Europe, Japan, and the United States using the cantilever construction method $[17,18]$. However, many studies focus on the preliminary design of such structures, instead of any details on the technical and economic aspects of building the main arch ring structures. When the same construction technique was introduced in China via direct reference of these form travelers in terms of structural dimensions and loads, the economy and working effects were far from ideal. Additionally, as the span increases, greater quantities of super-long buckles and anchor cables [3], as well as taller buckle pylons, must be used to control the equilibrium of the cantilever arch ring segments [19-21], in which case the main arch ring stress states are sometimes difficult to adjust due to the heavier cantilever segments, as well as long buckles and anchor cables with small tilt angles. Additionally, sometimes there are conflicts between the buckles and the form traveler when using the conventional form, where only buckles are used to control the arch ring tensile stresses. In addition to the erection control of the arch ring, the safety problem of the temporal buckle pylon arising from the cable stretching process should also be of concern in order to eliminate the risk of collapse. Especially during cantilever casting of the arch box-girder segment, it is very difficult to keep the centerline of the towering steel buckle pylon completely vertical at all times, and so safety problems arise in the buck-anchor system. Although many healthmonitoring systems have been established to observe the states of bridges in the operation stage [22-26], few studies have reported on the methods of safety control for the construction of temporal structures [27-29], such as high buckle pylons with super-long buckles and anchor cables, in promoting the cantilever casting construction of large-span concrete arch bridges in mountainous areas. As stated above, the methods for dealing with the technical and design upgrades of the temporary facilities during the main arch ring construction constitute the most important factor in the erection of large-span concrete box-type arch bridges [1]. Only by solving these technological issues can the designed structural shape and internal forces be efficiently achieved within a reasonable cost and safety range.

To give full play to the merits of this bridge type and taking into consideration the past experiences in Guizhou, new techniques for upgrading the temporary facilities were created. A new form traveler based on the feathers of such arch rings was invented to promote the erection efficacy, which further facilitates the technical upgrades, in terms of both the buckle-anchor system monitoring-control and temporary prestressing design in order to eliminate the difficulties brought by the span increase. The inverted-type triangle traveler composed of tiled main truss structures with a detaching walking hook and anchor tie rod is used to achieve space adaptability, light weight and modularization.
The semiautomatic deviation-rectifying system, which combines the technologies of real-time data collection of the buckle pylon deviations and automatic synchronized tensioning, is developed to ensure the safety of the buckleanchor system. Temporary short prestressed tendons are designed to control the large-span arch ring's tensile stresses. The new design and technologies were verified in the construction application of the Shatuo Bridge in Guizhou, China.

The remainder of the paper is organized as follows. Section 2 introduces the adaptive design and technologies of the temporary facilities of the Shatuo Bridge in terms of the new type of form traveler, the semiautomatic deviationrectifying control system, and the temporary short prestressed tendon design. Section 3 further discusses the implementation effects of the schemes. Finally, Section 4 provides the conclusions.

\section{New Techniques of the Temporary Facilities}

As the construction span of the concrete box-type arch bridge increases in mountainous areas, the form traveler should be accordingly designed to be heavier and larger in order to adapt to the cantilever casting method. Traditional form travelers will introduce more difficulties in terms of moving forward and line shape control. Additionally, the inconveniences of the equipment and larger tilt angles of the long buckle cables will hinder the safe controlling of the towering buckle-anchor system and introduce control difficulties in the main arch ring stresses, which make this design extremely expensive. Therefore, all types of erection control manners are ineffective or have low efficiency unless the technical bottleneck of the form traveler is overcome.

In this part, the disabilities of the traditional form traveler are first recognized. Then, based on the features of the Shatuo Bridge, a new type of form traveler system is adaptively developed. Finally, the supporting measures in terms of the buckle-anchor system control and temporary prestressing design can be established, as denoted in Figure 1.

\subsection{New Type of Form Traveler System}

2.1.1. Structural Design. The structure of the new form traveler is developed by combining the general features with those of the Shatuo Bridge. To illustrate their characteristics, the mainstream form travelers can essentially be divided into the European style, Japanese style, and Chuan style (invented by the Sichuan Luqiao Construction Group Co., Ltd., China, [11]), as shown in Figure 2. The main characteristics, advantages, and defects are listed in Table 1.

For the larger construction spans of main arch rings, such as the example in the Shatuo Bridge, it is not economical or efficient to directly use the form travelers in Table 1 because they are not able to simultaneously overcome the difficulties arising from long segments, steep slopes, a wide cross-section, heavy loads, and conflicts with the buckles. Thus, it is necessary to design a new type of form 


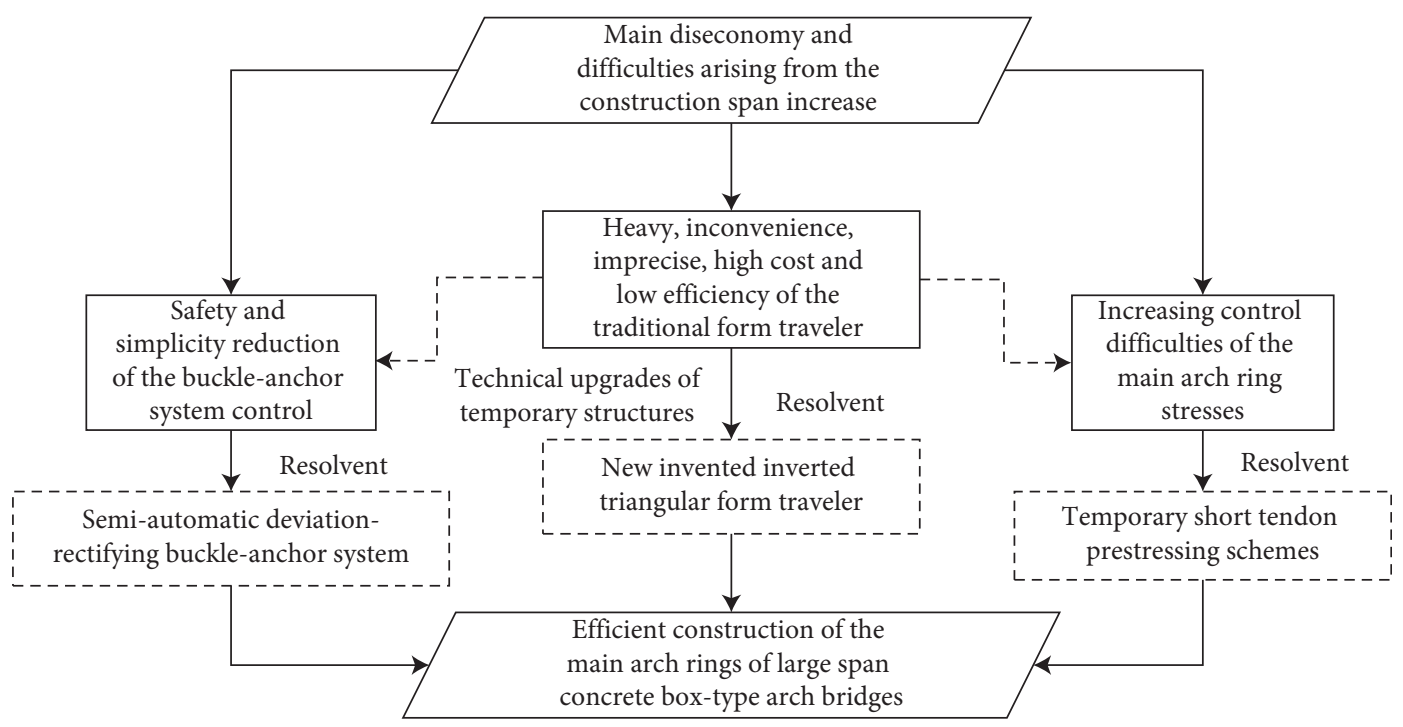

FIgURE 1: Adaptability design and control of temporary facilities for addressing the low efficiency issues of cantilever casting erection of mountainous concrete box-type arch bridges.

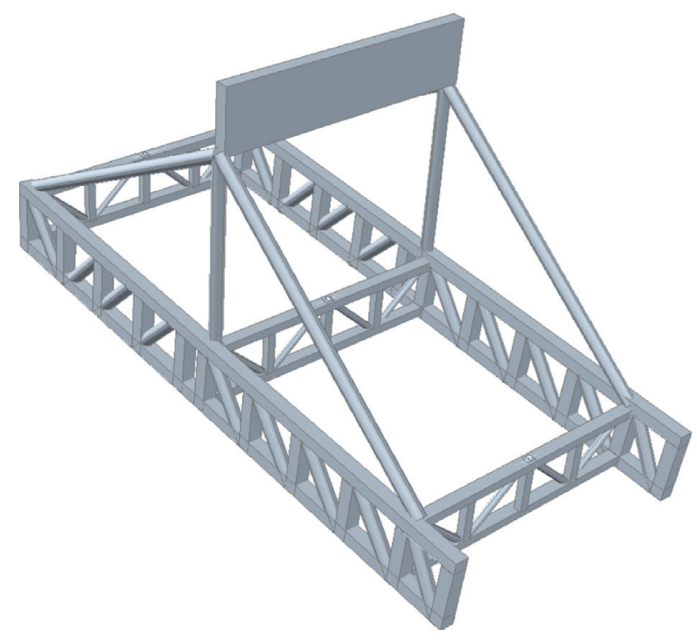

(a)

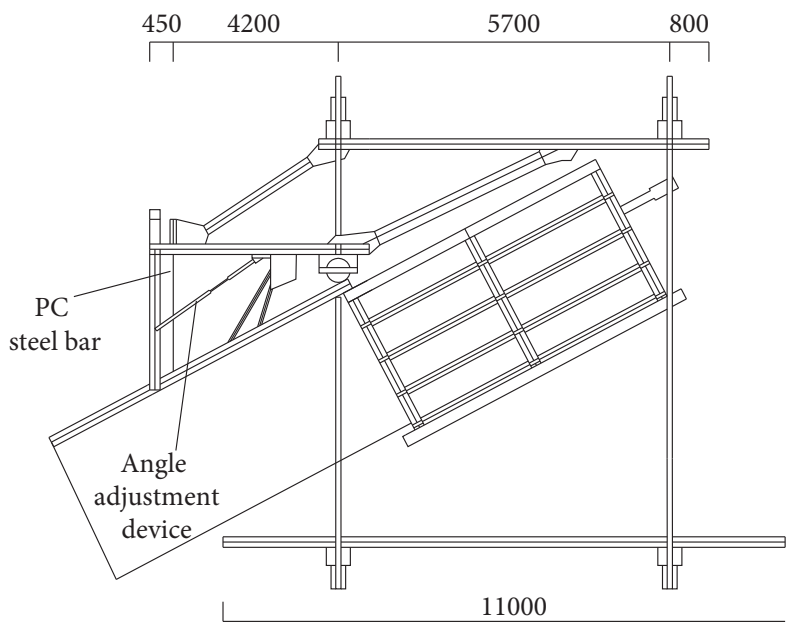

(b)

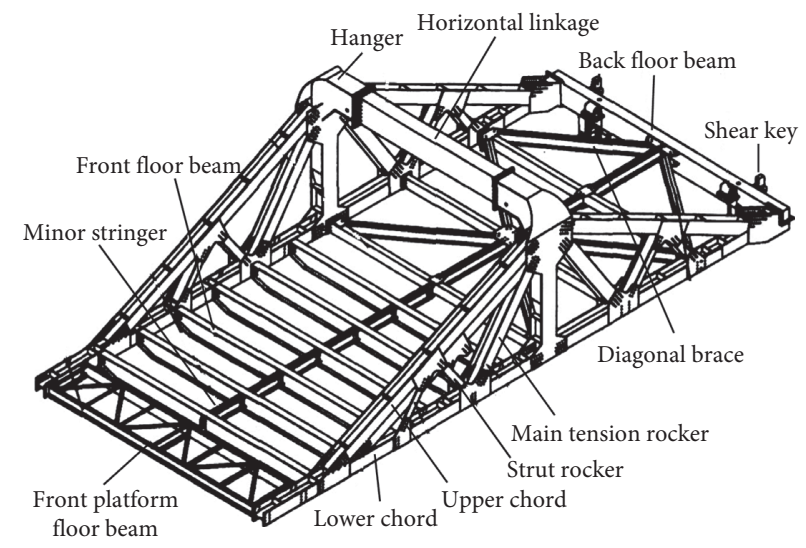

(c)

FIgURE 2: Structural diagrams of the mainstream form travelers (unit: mm). (a) European style. (b) Japanese style. (c) Chuan style. 
TABLE 1: Comparisons among different mainstream form travelers.

\begin{tabular}{|c|c|c|c|}
\hline $\begin{array}{l}\text { Form } \\
\text { travelers }\end{array}$ & Characteristics & Advantages & Defects \\
\hline $\begin{array}{l}\text { European } \\
\text { style }\end{array}$ & $\begin{array}{l}\text { Use truss bottom frame, with the side-stayed } \\
\text { bars hinged with the cross beams }\end{array}$ & $\begin{array}{l}\text { Lower center of gravity, } \\
\text { explicit force transmission, } \\
\text { and large capacity }\end{array}$ & $\begin{array}{l}\text { Huge deformations in the transverse mid } \\
\text { span of the front-end, difficult movement, } \\
\text { and blocking the buckles }\end{array}$ \\
\hline $\begin{array}{l}\text { Japanese } \\
\text { style }\end{array}$ & $\begin{array}{l}\text { Upstrike diamond-shaped form traveler, } \\
\text { evolved from adding an oblique pushing } \\
\text { device to the support positions of a traditional } \\
\text { one used for concrete continuous girder } \\
\text { bridges }\end{array}$ & Small deformation & $\begin{array}{l}\text { High center of gravity and excessive conflicts } \\
\text { with the buckles }\end{array}$ \\
\hline Chuan style & $\begin{array}{c}\text { Developed by simplifying the bottom frame of } \\
\text { the European style into a truss plane and } \\
\text { adding a hanger }\end{array}$ & Convenient movement & $\begin{array}{l}\text { Complex force transmission on the hanger, } \\
\text { cross beam subjected to huge forces and } \\
\text { carrying difficulties, and low capacity and } \\
\text { large deformation of the front-end of the } \\
\text { bottom plane }\end{array}$ \\
\hline
\end{tabular}

traveler to fulfill such requirements while being applicable to the Shatuo Bridge. The main idea can be described as follows.

To sweep the obstacles in the working space of the steel bar installation, formwork adjustment and installation, and concrete casting, the underneath type is adopted. On the basis, the upper chord of the main truss is used as the supporting structure of the bottom formwork crossbeams in order to increase the utilization effectiveness, and the main truss plane spacing should be adjusted to control the internal forces and displacements of the bottom formwork cross beam. The supporting system is then detached from the structure to adapt to different force transferring needs, and the hangers are only used for walking instead of being subjected to the casting loads. By the detachment of the supporting system, the traditional rule of "curve represented by straights" is converted to "curve represented by curves," which indicates a higher precision of the arch ring shape as well as its more aesthetically pleasing appearance. For the convenience of integrally hoisting the single main truss plane segment and in consideration of the maximum segment length of the main arch ring of the Shatuo Bridge, four main truss plane segments with inverted triangle forms are used. The main truss part is combined with the bottom truss part to increase the integral stiffness. An oblique strut is added to the center part to improve the stress distribution of the upper chord. For the convenience of movement manipulation of the form traveler, the walking system is set on the top of the main arch ring in order to drive the form traveler forward and backward through suspending the walking ships at the hanger top, which are located at the two sides of the structure. Through the abovementioned technical improvements, the structural weight is further reduced with the walking coefficient of 0.29 , with its structure shown in Figures 3(a)-3(c).

In the operational mode, the hydraulic center hole jacks are used to adjust the hangers up and down, while the moving forward and backward behavior are controlled by the hydraulic jacks set at the groove-shaped slipway. To resist the gliding force of the form traveller induced by the selfweight in the casting phase of the main arch ring segment, the holes in the bottom plate of the arch box are reserved for the square steel bolt to go through and support the slip-resistance key at the top of the upper chord of the main truss in order to stop the form traveler from gliding. The front-end elevation of the form traveler can be adjusted via the supporting jack set at the back-end, and the self-weight of the front part is balanced by the roller set at the back-end. The walking direction is controlled by the walking track of the hanger boat and the guide rollers, which are located at the two sides of the arch box. All the manipulations of the jacks are achieved by an oil pump and a set of control systems.

In the configuration, nine equal spacing spreader beams are located on the stringers to undertake the weight of the box-girder segment to be cast, with their numbering shown in Figure 3(d). The load distributions of the spreader beams are determined by the topology structure of the cross-section and the dip angles of the cantilever segment, as shown in Figures 3(e) and 3(f). Five typical segments of the main arch ring with dip angles ranging from 2.52 to 31.94 degrees are selected to compare their load distributions on the spreader beams. The average weight undertaken by the spreader beams in the web plate part are approximately twice the amount undertaken by that in the horseshoe chamfer part and the top and bottom plate parts, as shown in Figure 3(g). To ensure that the structure is safe, a beam system FE model with 196 nodes and 241 elements is established to simulate the typical loading states. Eleven kinds of cross-section are used, and the actual hinge joints are obtained by releasing 69 beam moment constraints, as shown in Figure 3(h). Then, the axial stresses, bending stresses, shear stresses, deformations, and stability factors are evaluated in Table 2. Since the control limits of the five indexes are set as $140 \mathrm{MPa}$, $145 \mathrm{MPa}, 85 \mathrm{MPa}, 20 \mathrm{~mm}$, and 4, respectively, according to the Chinese codes $[30,31]$, it can be seen that the truss structure is designed reasonably to transfer the vertical upper loads with an appropriate safety reserve.

2.1.2. Working Principle. To have a smooth working state, several technical details were designed in consideration of the inverted structure of the form traveler, as shown in Figure $4(\mathrm{a})$. The $\pi$-type walking track is connected to the anchor bolts, which are embedded at the top of the boxgirder to prevent the structure from sliding. Since the jack 

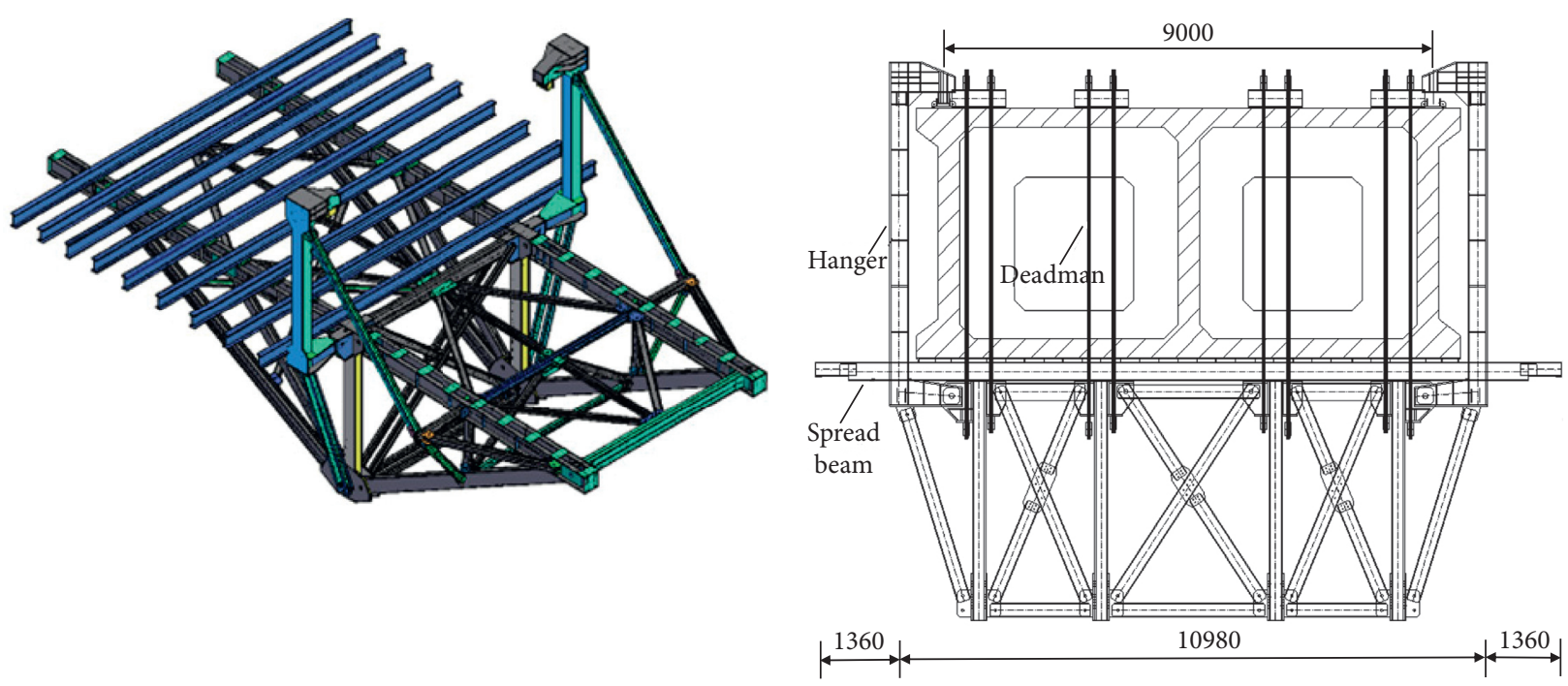

(a)
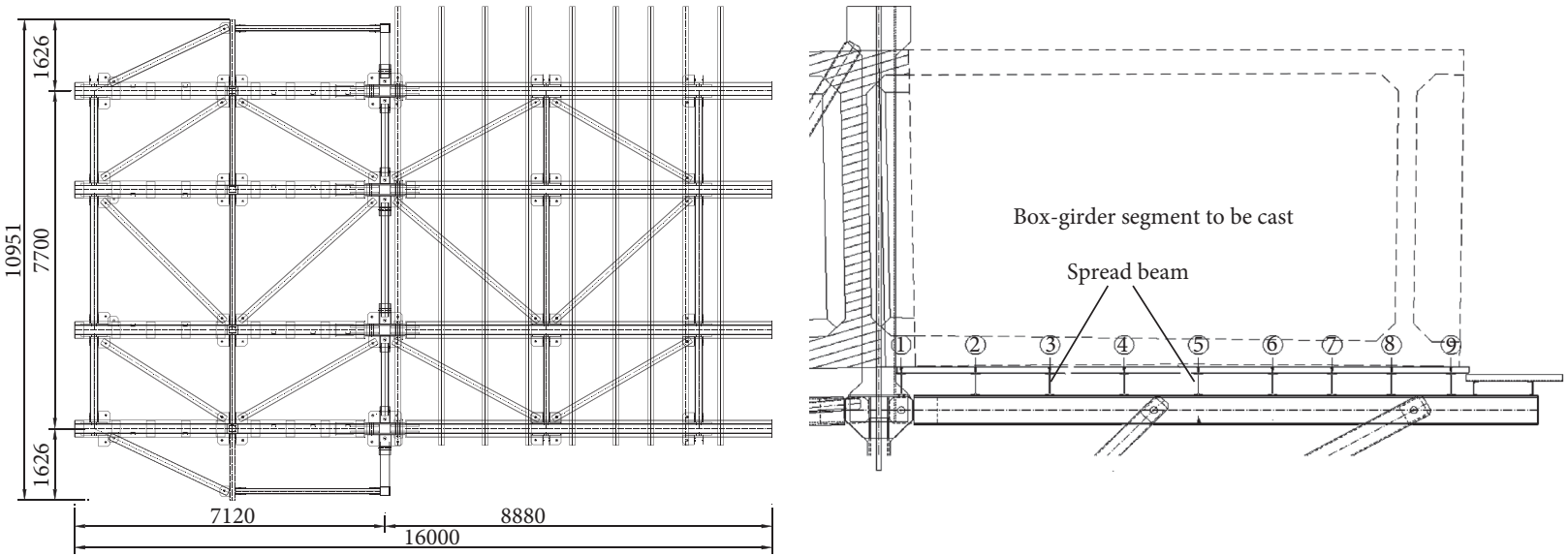

(c)

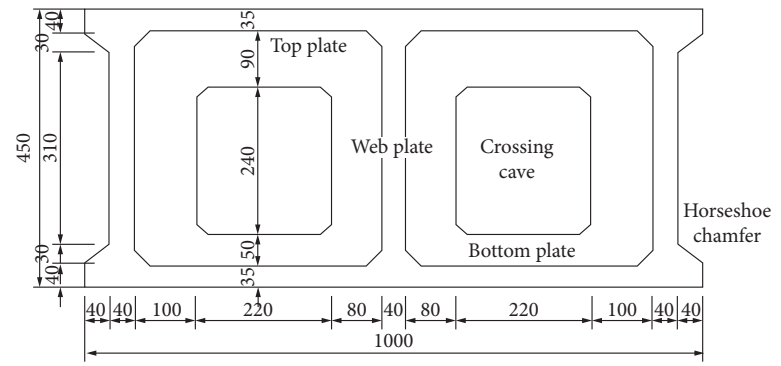

(d)

(e)

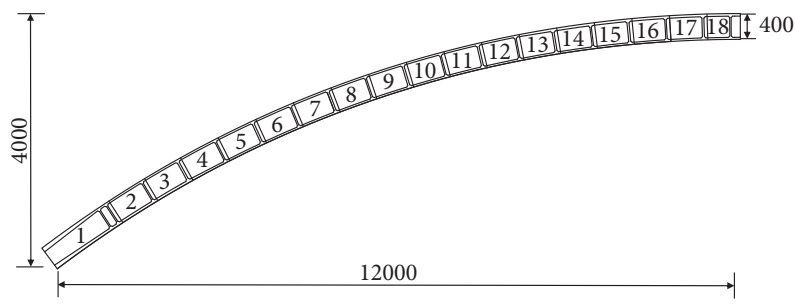

(f)

FIgURE 3: Continued. 


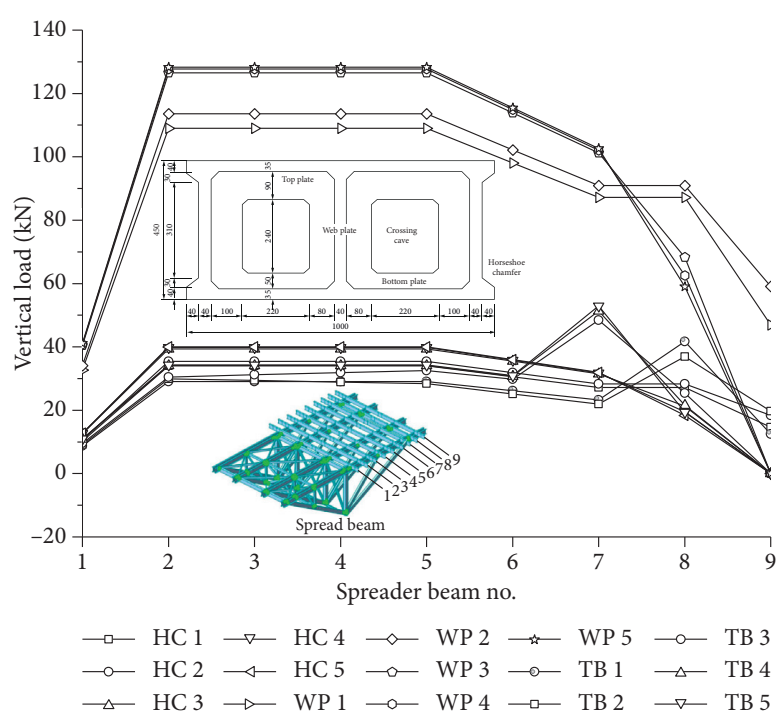

(g)

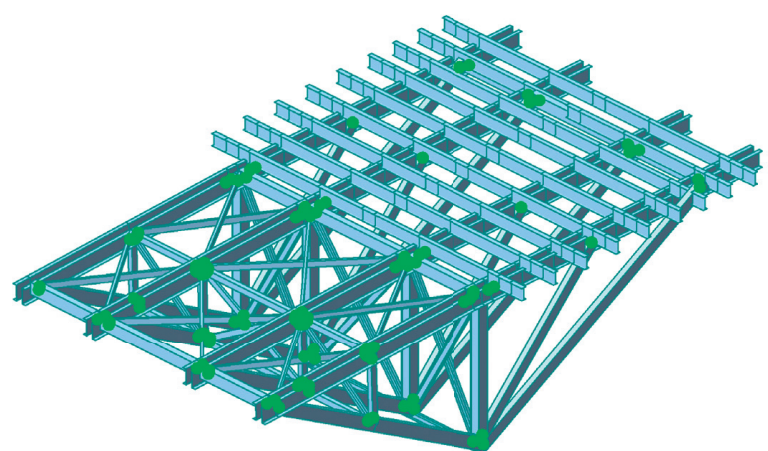

(h)

FIgURE 3: Force transmission rules of the inverted triangle form traveller. HC (i), WP (i), and TB (i) denote the spreader beams in the horseshoe chamfer area, web plate area, and top and bottom plate area in the no. i case $((\mathrm{i})=1-5)$, respectively. Cases 1 to 5 denote the cantilever box-girder segment loading of no. 2, no. 4, no. 13, no. 15, and no. 17 with the dip angles of 31.94, 27.83, 9.88, 6.17, and 2.52 degrees, respectively. (a) 3D view of the form traveler. (b) Profile (unit: $\mathrm{mm}$ ). (c) Plane (unit: $\mathrm{mm}$ ). (d) Numbering of the spread beams (unit: mm). (e) Typical cross-section (unit: $\mathrm{cm}$ ). (f) Numbering of the segments (unit: $\mathrm{cm}$ ). (g) Force distribution on the spread beams. (h) Constraint release of the FE model.

TABLE 2: Stress, stability, and deformation of the form traveler in typical cantilever loading cases. M denotes maximum and L and S denote the longitudinal beam and spread beam, respectively. Five cases are illustrated in Figure 3.

\begin{tabular}{lccccccccc}
\hline Case & $\begin{array}{c}\text { M axial } \\
\text { stress } \\
(\mathrm{MPa})\end{array}$ & $\begin{array}{c}\text { M bending } \\
\text { stress } \\
(\mathrm{MPa})\end{array}$ & $\begin{array}{c}\text { M shear } \\
\text { stress } \\
(\mathrm{MPa})\end{array}$ & $\begin{array}{c}\text { 1st order } \\
\text { stability } \\
\text { factor }\end{array}$ & $\begin{array}{c}\text { 2nd order } \\
\text { stability } \\
\text { factor }\end{array}$ & $\begin{array}{c}\text { 3rd order } \\
\text { stability } \\
\text { factor }\end{array}$ & $\begin{array}{c}\text { 4th order } \\
\text { stability } \\
\text { factor }\end{array}$ & $\begin{array}{c}\text { M deformation } \\
(\mathrm{mm})\end{array}$ & $\begin{array}{c}\text { Position of M } \\
\text { deformation }\end{array}$ \\
\hline 1 & 82.5 & 59.6 & 31.5 & 9.8 & 10 & 11.2 & 11.2 & 19.1 & End of L \\
2 & 84.7 & 58.7 & 31.5 & 9.8 & 10 & 11.2 & 11.2 & 20 & End of L \\
3 & 84.7 & 58.7 & 31.5 & 9.8 & 10 & 11.2 & 11.2 & 17.8 & End of no. 7 S \\
4 & 64.8 & 65.9 & 35.3 & 9 & 9.1 & 9.9 & 9.9 & 17.8 & End of no. 7 S \\
5 & 64.7 & 66.2 & 36 & 9 & 9.1 & 9.8 & 9.9 & 17.7 & End of no. 7 S \\
\hline
\end{tabular}

should perform the oil return repeatedly in order to finish a segment walking distance, a pushing box is designed to prevent the form traveler from sliding back at an oblique angle at the arch back. In casting, the shear key, which is located at the arch box bottom and can be lifted up into the structure at a moving state, is used to resist the downward pushing force. The trolley wheel reactions at the back end introduce the moment to balance the overturning moment induced by the self-weight of the structure.

As stated above, the operational procedure can be described as follows: (1) install the track before walking, relax the tension rod and jacks, and put the reaction roller in contact with the bottom of the arch box to simultaneously achieve mold unloading; (2) take away the shear arm and use the jack to push the steel box at the back of the limiting retaining track so the steel box transmits the force to the slip boat in order to drive the form traveler to move forward along the track; (3) when the jack oil returns, add a steel plate with an appropriate thickness between the steel box and slip boat and then insert the retaining pin to prevent the form traveler from moving backward; (4) as the jacks are pushing continuously, replacing the pins and lengthening the track, the form traveler continuously moves forward until reaching the next segment. Meanwhile, since the gravity position of the form traveler is forward, the roller at the back of the form traveler rolls as it moves; (5) when the form traveler walks in place, anchor the screw rod and jack up to make the reaction roller detach the bottom plane of the arch box. Then, pull down the shear arm to a certain level via the reserved hole in the bottom of the arch box, and insert the pins; and (6) install the formwork system, adjust the elevation, and cast the concrete to finish the next cycle. The form traveler is finally dismantled by the cable crane.

For ease of understanding, the force transferring of the inverted triangle form traveler is illustrated in Figure 4(b). The main longitudinal beam is located at the bottom of the box-type arch ring and connects to the already-casted concrete segment via the middle suspending point $\mathrm{B}$ and 


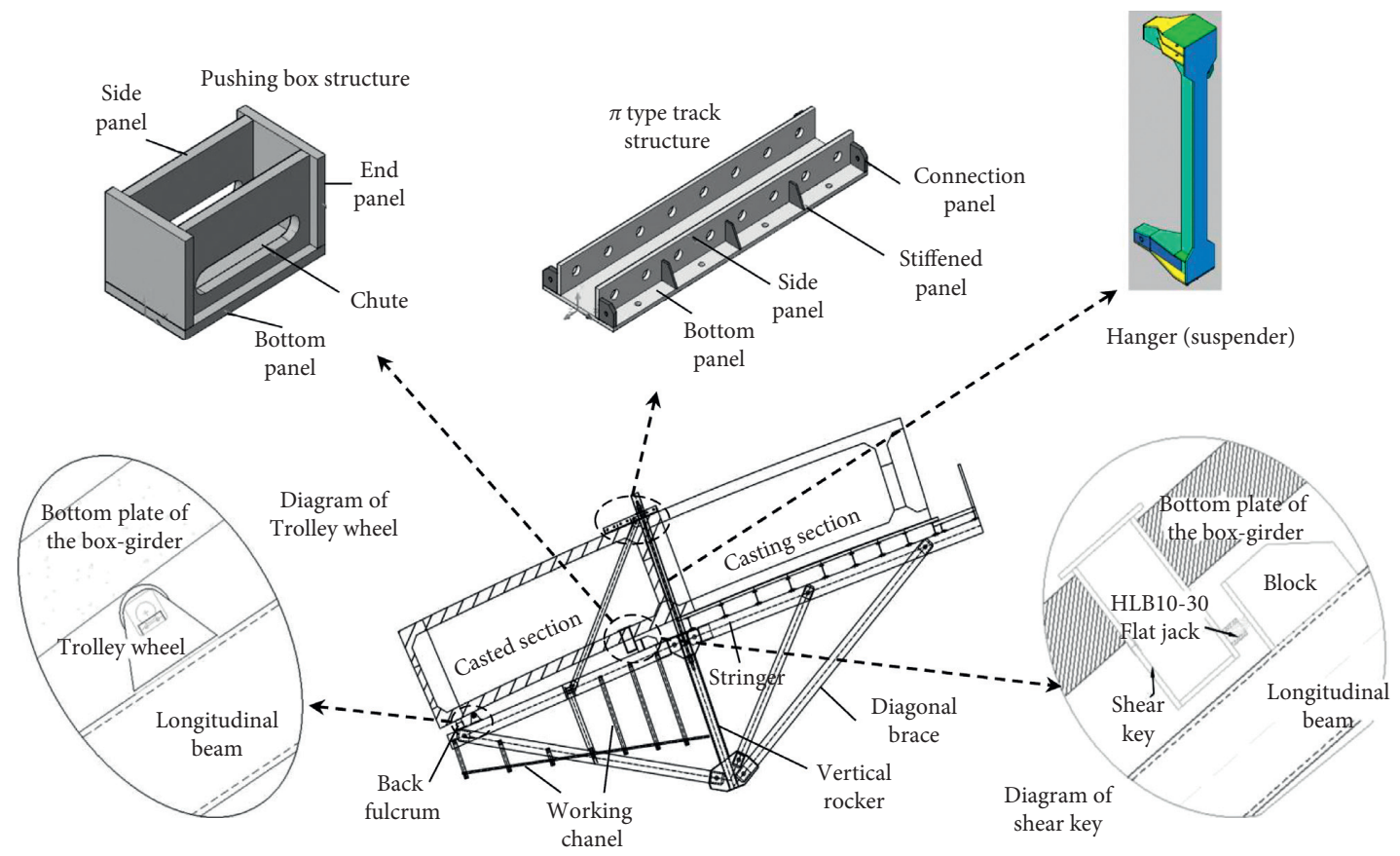

(a)
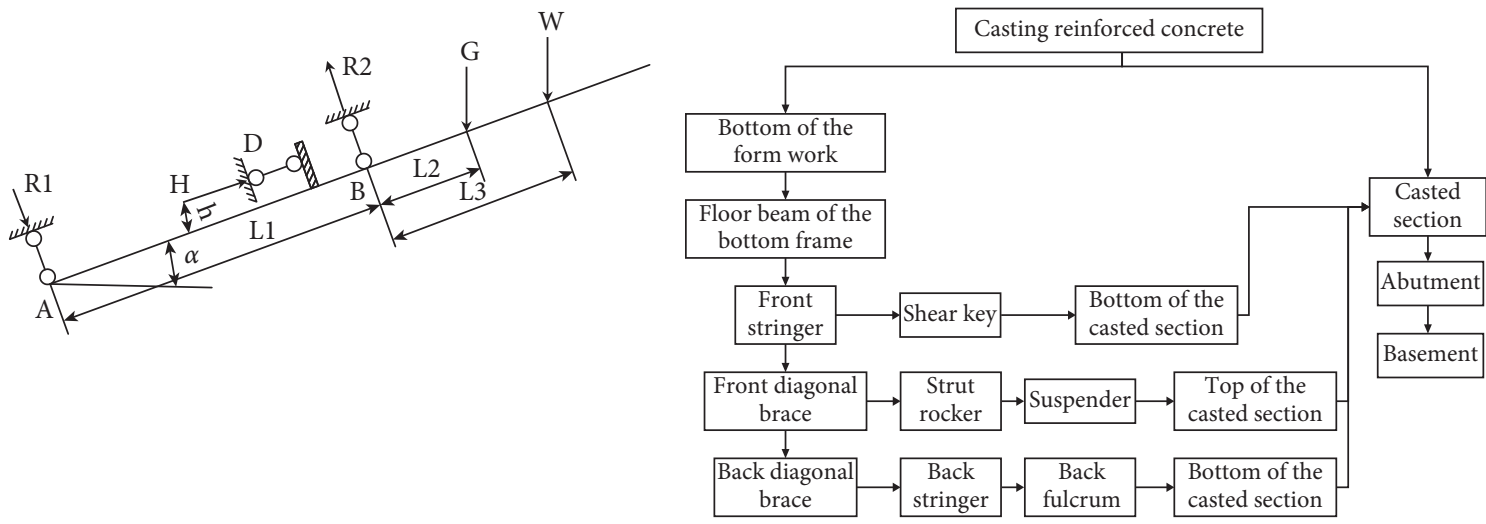

(b)

(c)

Figure 4: Technical details and force transmission rules of the inverted triangle form traveler. (a) Technical details of the form traveler. (b) Diagram of the force principle. (c) Force transferring of the members.

back anchor point $\mathrm{A}$, with the horizontal limiting retaining mechanism at point B. R1, H, and R2 are the relevant reaction forces on the form traveler resulting from the casted concrete segment, and $\mathrm{G}$ and $\mathrm{W}$ are the self-weights of the form traveler (including the construction loads) and segment to be casted, respectively. The force transmission process of the form traveler members during concrete casting is shown in Figure 4(c).

\subsection{Semiautomatic Deviation-Rectifying Buckle-Anchor} System. As previously stated, the new type of form traveler can address the efficiency and precision of the cantilever installation as well as the conflicting problems between the buckle cables and the old-style form travelers. On this basis, the operation of the complex buckleanchor system is able to be controlled more reliably in order to ensure its safety and stretching efficacy with the establishment of a semiautomatic deviation-rectifying buckle-anchor system. Here, "semi" means the system still needs to work under the supervision of field engineers for intervention at any time, in case the preset values need to be adjusted or unpredictable events occur in the complex environments.

2.2.1. Structure of the Buckle-Anchor System. The buckleanchor system has four parts: the buckle tower, the buckle anchor cable and its anchoring structure, and the ground anchor. It is a temporary structure used to balance the structural self-weights and control the shape of the main arch ring as well as the internal forces of the structure during the main arch ring cantilever construction, as shown in Figure 5(a). 


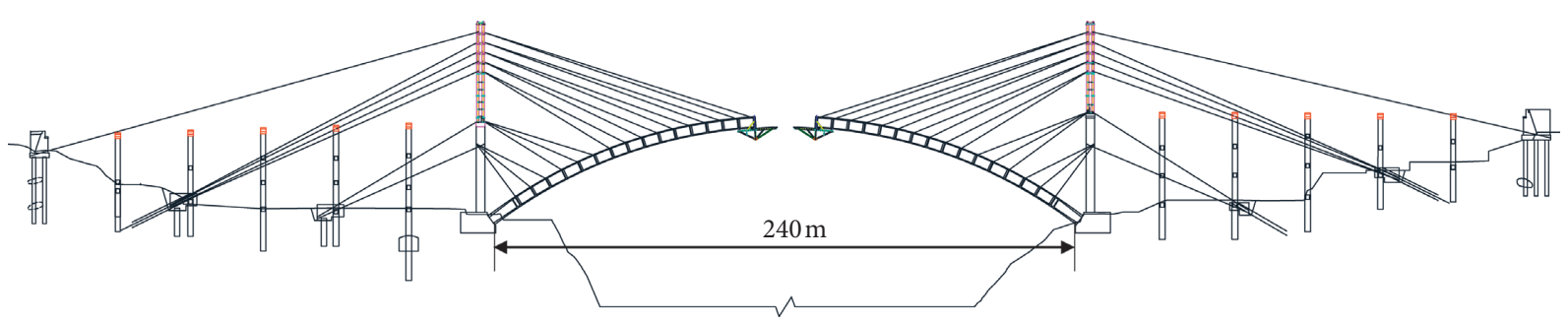

(a)

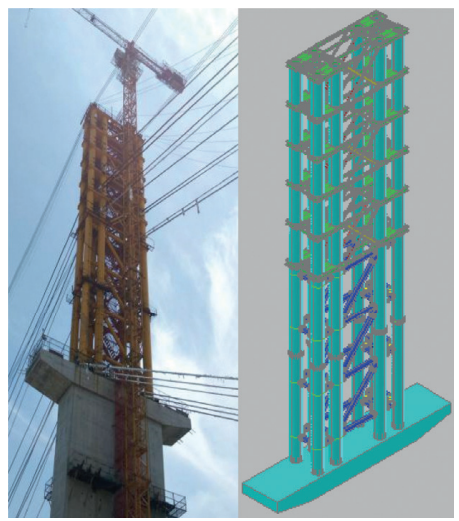

(b)

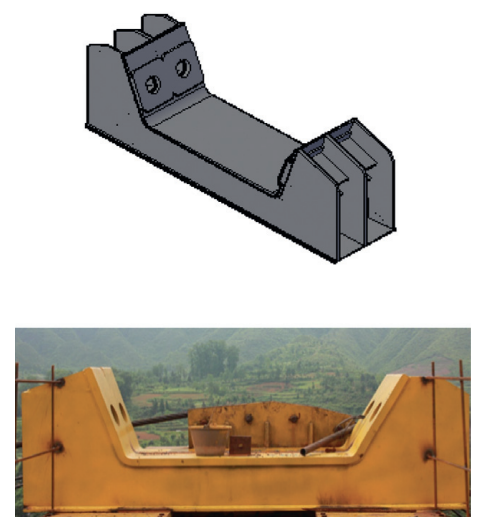

(c)

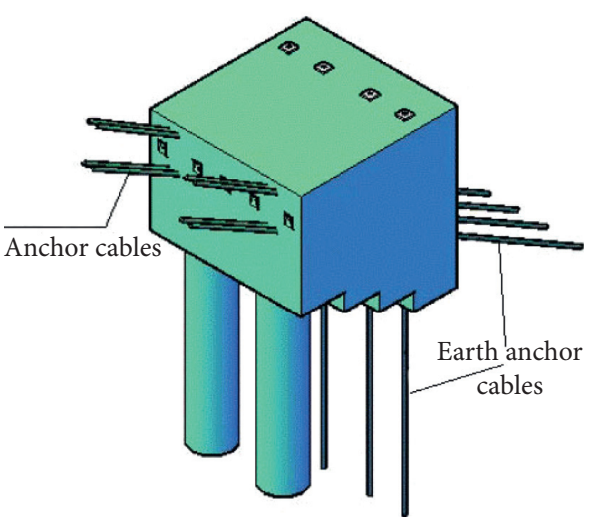

(d)

FiguRE 5: Structure of the buckle-anchor system. (a) Layout of the buckle-anchor system. (b) Steel buckle tower. (c) Steel anchor box. (d) Earth anchor.

The buckle tower is divided into upper and lower parts. The lower part is the bridge pier on the abutment, and the upper part is a steel structure tower. The buckles and anchor cables of no. 2 to 7 segments are hung on the piers, and those of the no. 8 to 18 segments are hung on the steel buckle tower. The tower consists of eight steel pipe columns, in which four are taken as a group, and each column is connected by the steel members to form a whole part, as shown in Figure 5(b). The bottom of the steel buckle tower and the top surface of the pier are consolidated with pre-embedded bolts. The crosssectional dimensions of the components are determined by the structural force requirements. The buckle-anchor cable system consists of the buckle cables, anchor cables, steel anchor box, and the anchor. There is a set of buckles and anchor cables for each main arch ring segment. The buckle anchor cables are all made of $\varphi s 15.24$ high-strength and lowrelaxation steel strands with a standard tensile strength of $1860 \mathrm{MPa}$ and a safety factor $\geq 2.0$. The steel anchor box shown in Figure 5(c) is welded by the steel plate for anchorage of the buckle and anchor cables. The tension ends are placed at the buckle pylon, with an antiretraction device arranged on the anchor to prevent the buckle and anchor cables from losing effectiveness. The front-end of the main arch ring segment and the earth anchor are taken as the anchorage ends using the P-type extruding anchor. The pylon and abutment are made full use of in order to balance the horizontal and uplift forces of the anchor cables, with the anchor ends of the cables placed at the caps. Then, the vertical and oblique prestressed tendons are installed to the pylons and abutments to resist the horizontal and uplift forces together, as shown in Figure 5(d).

\subsubsection{Automatic Deviation-Rectifying Control System.} Based on the configuration of the buckle-anchor system, we developed an automatic system to control the deviation of the buckle pylon introduced by the tensioning process of the buckles and anchor cables. Assuming that the deviation of the main pylon is zero before tensioning, the relationships among the lengths, angles, and elongations of the buckle and anchor cables are first analyzed, and then the horizontal force balance between the buckle and the corresponding anchor cable can be achieved by controlling the tensioning speed of the jack, which ensures that the pylon does not deviate from the vertical place. Meanwhile, the deviation is monitored by a control center that can send instructions for adjustment of the tensioning forces and the speed of the buckles and anchor cables based on the monitoring data.

Following this principal, two sets of control systems need to be built: the dynamic pylon deviation observation system and the automatic cable force adjustment control system, which are mainly involved in displacement monitoring, data transmission, processing, and instruction issuing.

In the former system, the basic route for measuring the pylon deviation can be illustrated in Figures 6(a) and 6(b). The points $\mathrm{A}, \mathrm{B}$, and $\mathrm{C}$ denote the installation position of the detector, the measuring datum point, and the measuring point after deviation, respectively. $\mathrm{BC}, \mathrm{CD}$, and $\mathrm{CE}$ are the actual deviation, measuring elongation, and longitudinal deviation, respectively. $\alpha$ and $\alpha 1$ denote the settable original installation angle and the angle after deviation, respectively. The detectors are installed longitudinally along the bridge with an installation angle of $3^{\circ}$. As seen, $\alpha \approx \alpha 1, \mathrm{BC}=\mathrm{CD} /$ $\cos \alpha 1$, and $\mathrm{CE}=\mathrm{BC} \cdot \cos 3^{\circ}$. If we, respectively, define the 


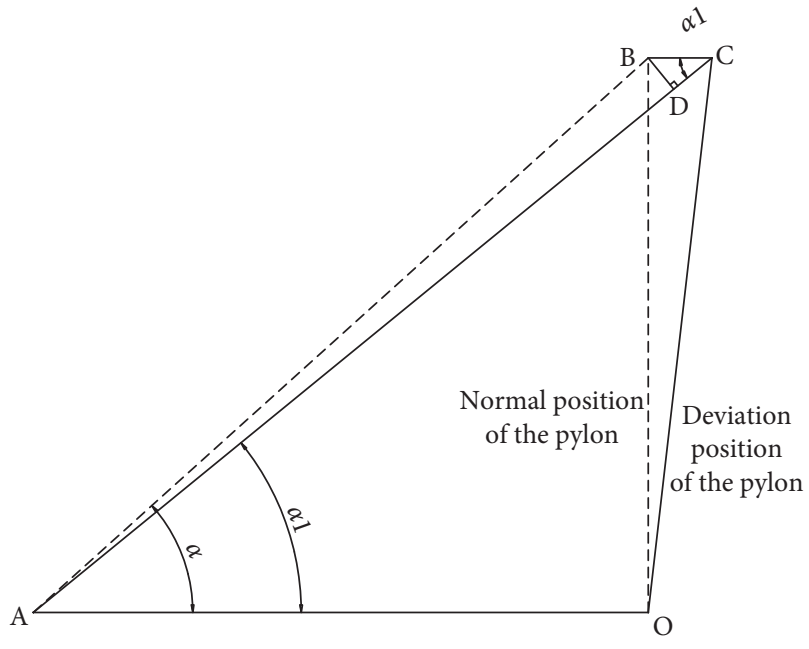

(a)

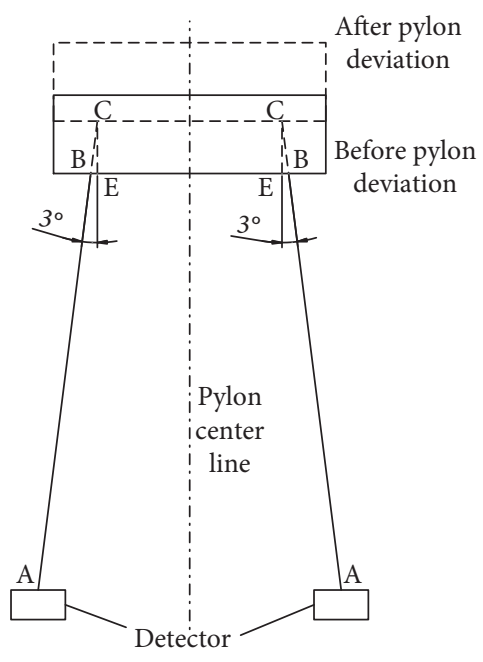

(b)

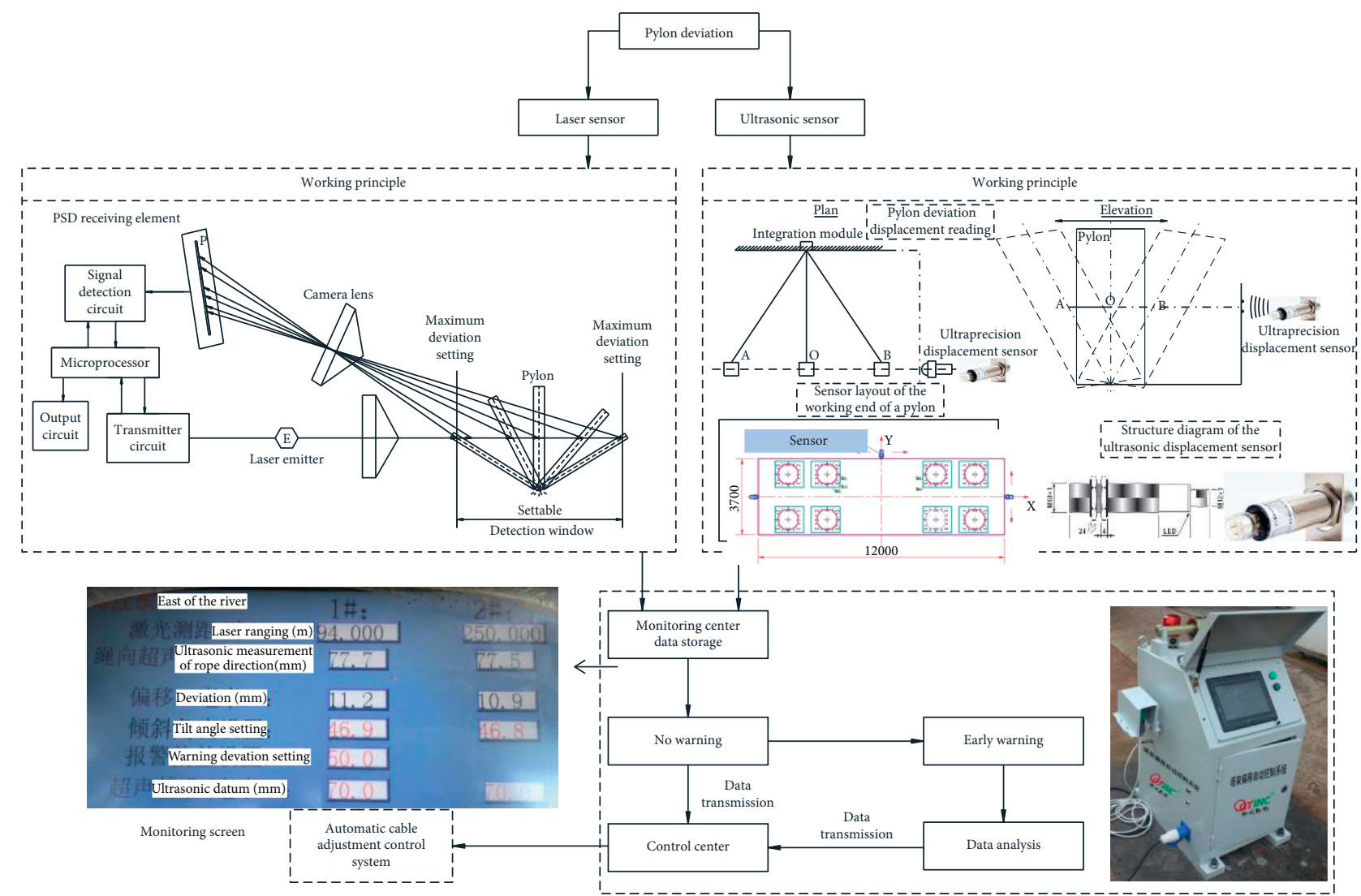

(c)

FIGURE 6: Working principle of the dynamic pylon deviation observation system. (a) Elevation diagram of the pylon deviation. (b) Elevation diagram of the pylon deviation. (c) Flow of the pylon deviation monitoring system.

pylon deviation and the measuring increment variable as $\delta$ and $\Delta L$, the following relationship holds.

$$
\delta=\Delta L \cdot \frac{\cos 3^{\circ}}{\cos \alpha 1^{\circ}}
$$

To achieve this aim, an integrated pylon deviation automatic control system combined with ultrasonic displacement sensors, laser ranging sensors, and some conductive elements is established, as shown in Figure 6(c). The system is able to automatically perform a real-time collection of the deviation data with a resolution of $1 \mathrm{~mm}$ and issue an early warning if the deviation is beyond the preset value according to the design requirements, e.g., $30 \mathrm{~mm}$. The data will be fed back to the control center to determine the deviation-rectifying instructions. The monitoring display is composed of a touch screen computer 
integrated into the electric control cabinet of an intelligent pumping station system, the corresponding pressure sensor module and the control cables. The cabinet is installed with the PLC control element and analog acquisition module for processing of the collected data.

The ultrasonic displacement sensor is used to measure the horizontal distance induced by the pylon deflection with a high precision. It adopts the standard industrial electrical interface output of $4 \sim 20 \mathrm{~mA}$ and is able to precisely compensate for the temperature errors with a resolution of $0.1 \mathrm{~mm}$. The sensor also has a strong capacity for being subjected to wind, rain, impact loads, and signal jamming, with a wireless bluetooth connection distance as long as $2000 \mathrm{~m}$. As seen, the sensors were installed and numbered at the outer edges of the pylon; there were two for the end surfaces along the $X$-axis and one for an end surface along the $Y$-axis. The former measured the longitudinal deviation, while the latter measured the transverse deviation in a realtime manner. The distance between the $\mathrm{A}$ and $\mathrm{B}$ points were set as the allowable maximum deviation value, with the $\mathrm{O}$ point denoting the initial position of the pylon. The allowable value was determined by the design requirements.

The laser ranging sensor is designed based on Optical Triangulation Theory. The emitter projects the visible laser via the camera lens to the target object, and the reflected laser is received by the PSD element via the receiving lens. The actual distance to be measured between the receiver and the object can be determined by the analog and digital circuits along with the microprocessor according to the angle of the beam arriving at the receiver. Thus, two sensor reflectors for the bridge were installed at the left and right sides of the pylon top, and the carbon fiber rope measurement was used to aid the displacement monitoring.

The automatic cable force adjustment control system is used according to the processing data of the control center resulting from the pylon deviation monitoring system, together with some preset values prescribed by the prior design or safety requirements, in order to achieve an automatic realtime monitoring-control function of the buckle and anchor cable tensioning, at least for each construction step, as shown in the site in Figure 7(a). It is composed of multifunction combination jacks, a hydraulic pump station, automatic tool anchors, pressure sensors, and a control system, as well as some data cables, as denoted in Figure 7(b).

By using the multifunction combination jack, all the steel strands will, overall, go through two stages of tensioning: the preloading stage and the integral cable tensioning stage. The latter may also involve automatic cable tension adjustments determined by both the preset control values and the realtime data exchange between the sensors and the control center, as illustrated in Figure 7(c). In the preloading stage, the control center issues the instruction to open the one-way valve of the oil intake line of the preloaded jack and close that of the tension jack. The piston of each preloaded element elongates to drive the single-hole automatic tool anchor with clamp pieces moving forward to tension the steel strand. The piston will automatically return the stroke for the next turn as soon as it elongates with one stroke. In the returning stroke, the clamp pieces of the tool anchor are restored via the resetting spring, whereas those of the automatic tool anchor of the integral tension jack simultaneously self-lock to prevent the strand from falling back via the resetting spring. This procedure will repeat until all the tensions of the target steel strands reach the preset value. Similarly, in the integral cable tensioning or adjustment stage, the one-way valve of the oil intake line of the tension jack opens, while that of the preloaded jack closes. The tension jack drives the automatic tool anchor back and forth until all the cable tensions reach their preset values.

During segment casting, as the concrete weight increases, the buckle pylon will tilt to the middle span direction. Once the deviation is beyond the preset limit value, the control center will issue an early warning along with a rectification tension increment instruction for both the buckle and anchor cables, in order to correct the position of the pylon to a safe range, as well as to retain the elevation of the cantilever segment at a suitable tensioning speed.

Conforming to the working manners, in the cantilever casting construction, the Shatuo Bridge employed two sets of control systems for the left and right banks, two sets of pumping stations that include two main stations and two auxiliary ones with the control system installed on the main ones, and a total of 24 sets of 650 -ton tension adjustment jacks. One pumping station can control two sets of jacks, and the main ones were connected to the auxiliary ones via bluetooth wireless technology, by which a set of pumping stations was able to synchronously drive four sets of jacks. The tension error of the jack, the displacement error of the automatic tool anchor, the synchronized displacement error, and the tension error were all within $0.2 \mathrm{MPa}, 2 \mathrm{~mm}, 2 \mathrm{~mm}$, and $1 \%$, respectively. Figure 8 presents the field test results of the automatic deviation-rectifying control system in the west bank cantilever casting during the interval from the no. 9 to no. 15 segments, as denoted in Figure 3(f).

Although the designed tension forces may have been determined by construction calculations, the actual deviations were far from conforming to the ideal pattern due to the complexities of the construction step, which involves the 3D flexibility of the pylon, tensioning errors (e.g., introducing the transverse inconsistency of the deviation), contact nonlinearity of the buckle cables, the casting process, and moving forward of the form traveler. It is difficult to develop a completely reliable FE model to correctly include all of these facets for the safety control of the temporary structure. We still have to pay identical attention to the deviation at both the upstream and the downstream sides. As the deviation limit value is preset at $50 \mathrm{~mm}$ in consideration of the security redundancy of the buck pylon, it can be seen that the deviation was beyond the limit for six observation time points with the maximum value reaching almost $-75 \mathrm{~mm}$. In fact, once the control center received the deviation data within the lowest time interval, a series of minimum tension increment instructions were successively sent to the automatic cable adjustment control system with a warning issued to adjust the real-time controlled cable tensions (mainly the anchor cables) at a preset speed until the pylon went back to the safety range. However, the deviation-rectifying responses differed in different cases 


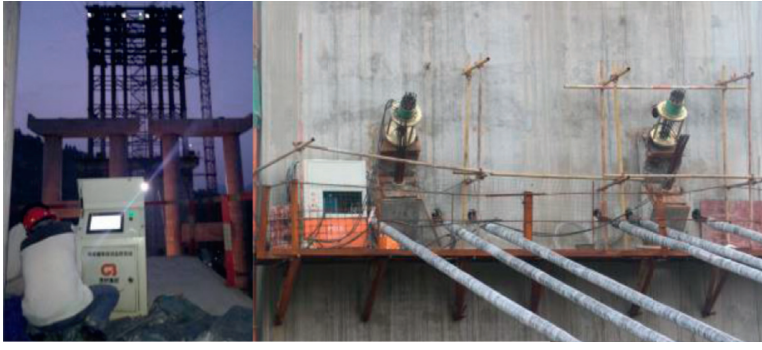

(a)

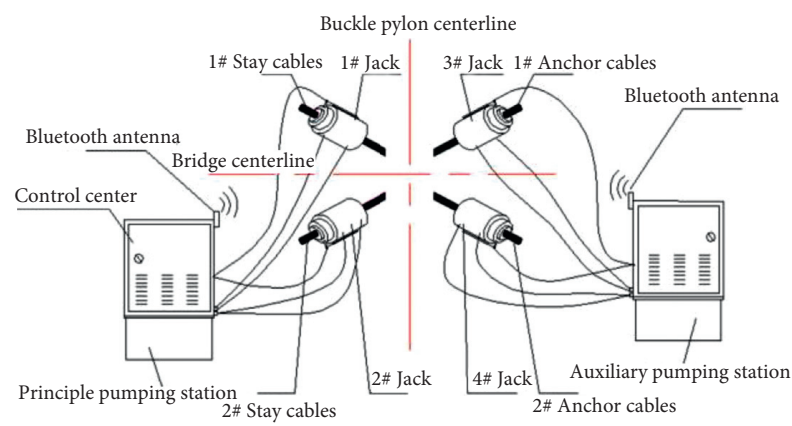

(b)

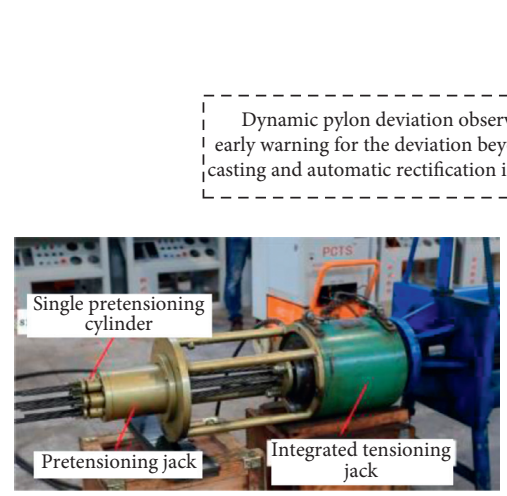

Multi-function combination jack

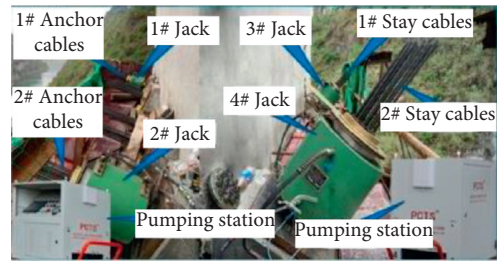

Touch screen: set the preload of the steel strands set the control tension forces or displacements of the tensioning

set the con

system:

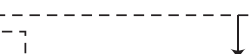

Control center 7 $\downarrow$
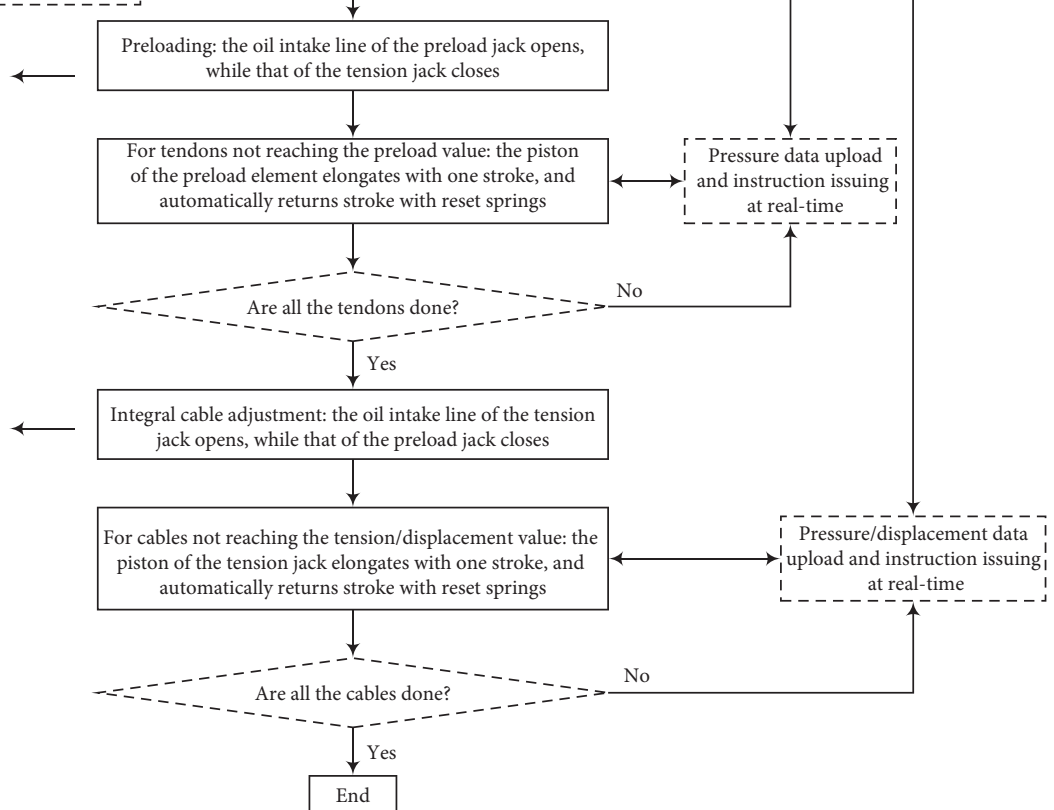

(c)

FIGURE 7: Working principle of the automatic cable adjustment control system. (a) Automatic monitoring-control of the cable tensioning. (b) Components of the automatic cable adjustment control system. (c) Principle of automatic preload and integral tensioning.

because time delay might not have been completely avoided in a wireless tensioning manner. As soon as the pylon was restored to the safety state, the deviation-rectifying manipulation was automatically ceased for a continuing normal cable tensioning that was predetermined by the construction design. The deviation variations from the solid marks (RI 1 to 6) to the hollow marks are induced by a combination of two such instructions. As a result, the system performed well in safely controlling the buckle-anchor system in an intelligent and efficient manner.

2.3. Temporary Short Prestressed Tendon Design. Control of the arch ring line shape and tensile stresses is the key to erecting the main structure of the Shatuo Bridge, and all the techniques mentioned above were established to serve that end. However, these technical upgrades were not sufficient for the arch ring state control, because conventional adjustment of the arch ring state depending on the buckles is no longer efficient due to the heavier cantilever segments and smaller tilt angles of long buckles induced by a span increase.

To overcome the tensile stresses appearing at the top and bottom plates of the arch ring box-girder in an alternative manner during cantilever casting, the temporary short prestressed tendon schemes were first proposed.

The prestressing design method for general straight concrete girders [11] can be extended for that of an arch ring segment. According to the force equilibrium of the equal cross-section arch ring segment of the Shatuo Bridge in the $X-Y$ coordinate system, as illustrated in Figure 9(a), the bending moment $M_{i}$ and shear force $V_{i}$ introduced by the self-weights and temporary loads at end $i$ can be derived as 


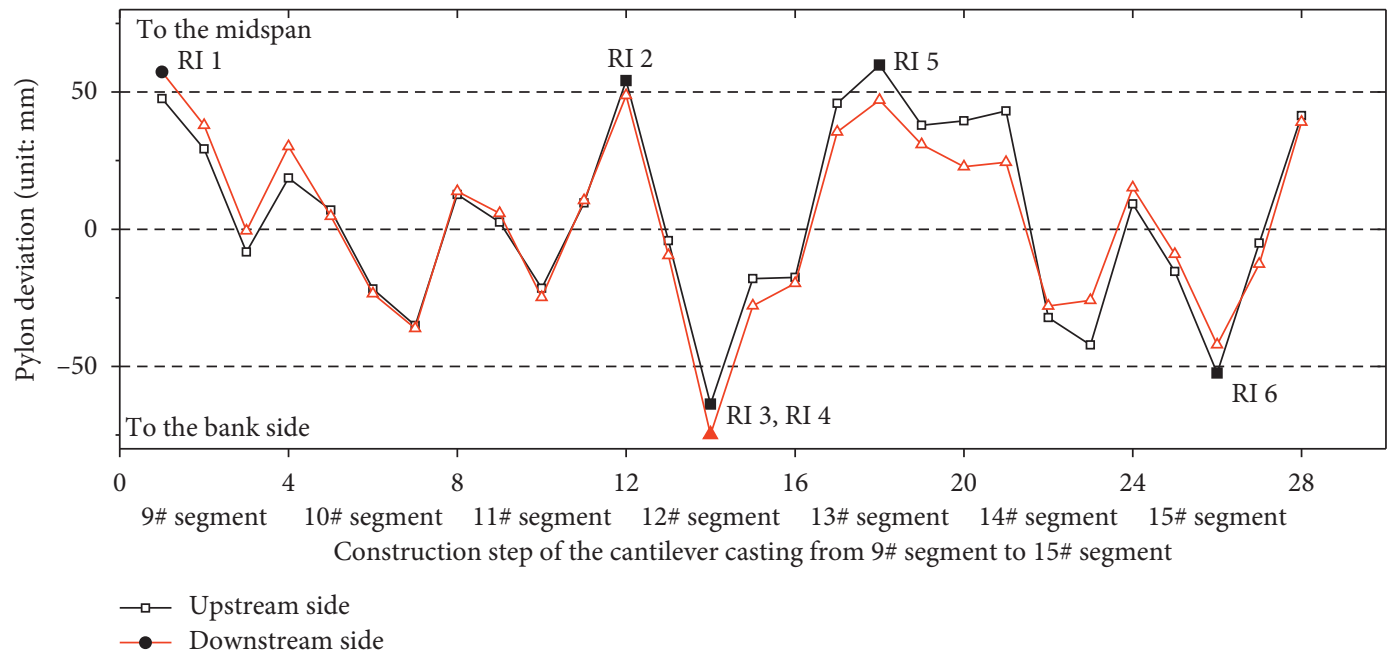

FIGURE 8: Field test of the automatic deviation-rectifying control system in safety control of the west bank cantilever casting construction of the Shatuo Bridge (unit: $\mathrm{mm}$ ). RI denotes that automatic rectification intervention was initiated. The installation of each box-type segment is composed of four tensioning construction steps, before casting, after casting, before tensioning, and after tensioning, and the designed tension forces were predetermined by the construction design.

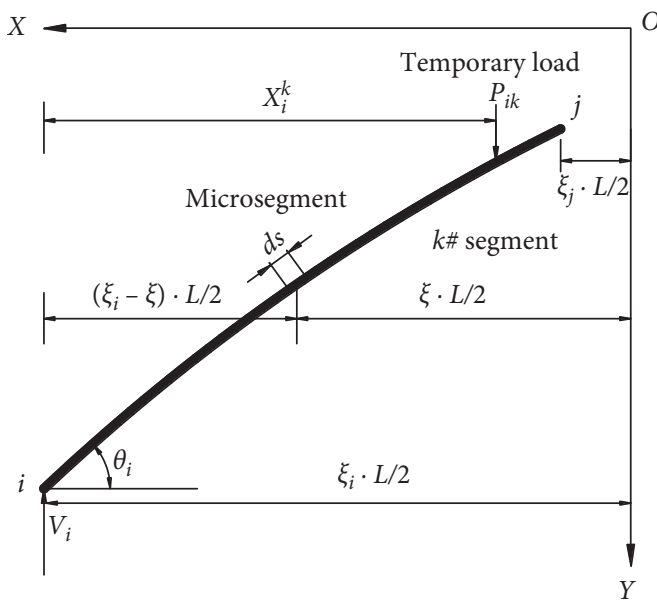

(a)

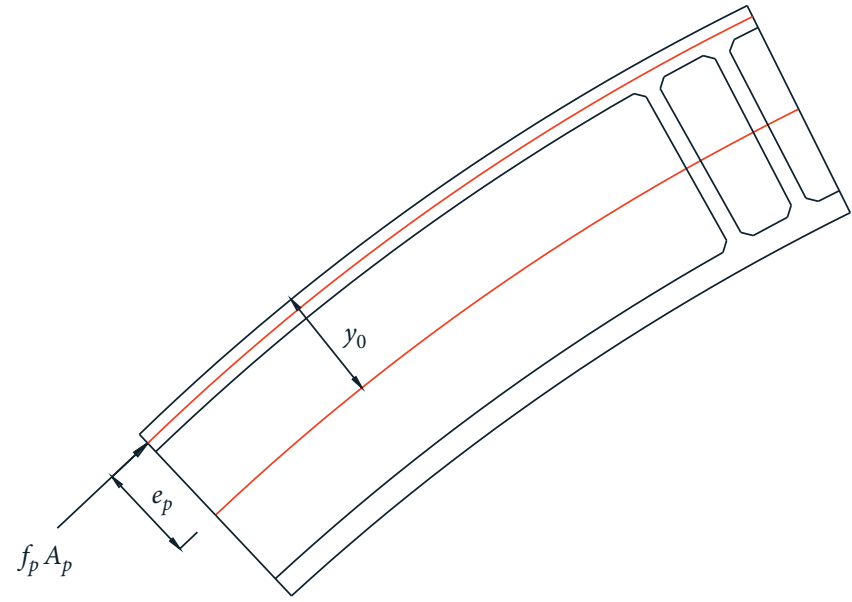

(b)

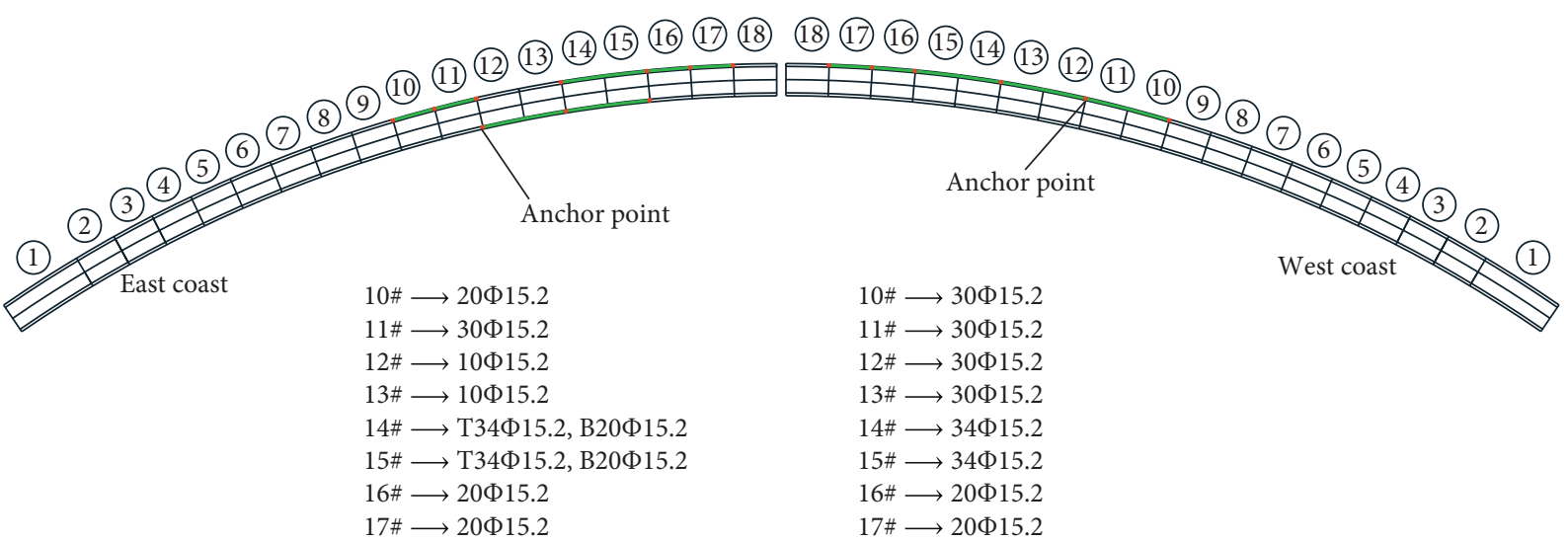

(c)

FiguRE 9: Principle of temporary short prestressing design for the main arch ring segment and tentative layout of the prestressed tendons for the field test study. T, B denote the top and bottom plates of the arch box-girder, respectively. (a) Force equilibrium of no. $k$ arch ring segment. (b) Diagram of arch ring prestressing. (c) Longitudinally different patterns of prestressed tendons for field test study. 


$$
\begin{aligned}
M_{i}= & M_{i}^{s}+M_{i}^{p}=\frac{A \cdot L^{2}}{4} \cdot \gamma \cdot \int_{\xi_{j}}^{\xi_{i}}\left(\xi_{i}-\xi\right) \\
& \cdot \sqrt{1+\eta^{2} s h^{2} K \xi} \cdot d \xi+\sum P_{i k} X_{i}^{k}, \\
V_{i}= & Q_{i}^{s}+Q_{i}^{p}=\frac{L}{2} \cdot \gamma \cdot A \cdot \int_{\xi_{j}}^{\xi_{i}} \sqrt{1+\eta^{2} s h^{2} K \xi} \cdot d \xi+\sum P_{i k} .
\end{aligned}
$$

where $\eta=(2 K f /(L(m-1)))$ and $K=\ln \left(m+\sqrt{m^{2}-1}\right)$ hold for the coefficients $M_{i}^{s}, M_{i}^{p}, Q_{i}^{s}$, and $Q_{i}^{p}$ denote the selfweight-induced bending moment, the temporary loads-induced bending moment, the self-weight-induced shear force, and the temporary loads-induced shear force with respect to end $i$, respectively. $L, f, m, A$, and $\gamma$ are the calculation span, rise, arch axis coefficient, cross-sectional area, and material density of the arch ring, respectively. Here, $\xi$ denotes a kind of scale factor. $P_{i k}$ and $X_{i}^{k}$ denote the $k$ th external load and its horizontal distance to end $i$, respectively.

It can be specified that the positive sign denotes compressive stresses and the negative sign tensile stresses, then the resultant normal stresses at the upper edge and lower edge of the cross-section, referred to as $\sigma_{t i}$ and $\sigma_{b i}$ can be, respectively, written as

$$
\begin{gathered}
\sigma_{t i}=\frac{M_{i}}{I_{i}} \cdot y_{t}-\frac{V_{i} \cdot \sin \theta_{i}}{A}, \\
\sigma_{b i}=-\frac{M_{i}}{I_{i}} \cdot y_{b}-\frac{V_{i} \cdot \sin \theta_{i}}{A},
\end{gathered}
$$

where $I_{i}, y_{t}, y_{b}$, and $\theta_{i}$ are the moment of inertia, the distances from the centroid to the upper and lower edges, and the horizontal angle at end $i$, respectively.

If the prestressed tendons, with cross-sectional area $A_{p}$ and distance $e_{p}$ from the resultant point to the net crosssection gravity axis, are arranged at the segment as shown in Figure 9(b), the prestressed stress at the upper edge can be expressed as

$$
\sigma_{t p}=-\frac{f_{p} \cdot A_{p}}{A}-\frac{f_{p} \cdot A_{p} \cdot e_{p}}{I_{i}} \cdot y_{0} .
$$

The reinforcement area should then satisfy the control condition:

$$
\sigma_{t}=\sigma_{t i}+\sigma_{t p} \leq\left[\sigma_{t}\right]
$$

where $\left[\sigma_{t}\right]$ denotes the stress control index, which should also include some safety reserve factors.

The no. 10 to 17 segments were selected to test the schemes, and they were preliminarily analyzed based on the abovementioned formulas. Taking the east bank case as an example, if only eliminating the alternating tensile stresses, the reinforcement results are close to one another among the segments; that is, 12 to 15 prestressed tendons each with $7-\varphi 15.2 \mathrm{~mm}$ steel strands were necessary for either the top or the bottom plate of the arch ring box-girder. From an economic perspective, three patterns of arrangements, including prestressing in the top plate, the bottom plate, and in both plates along with suitable tensioning manners may theoretically be considered for reducing the tensile stresses to some extent. This was a chance to test the prestressing effects of different tendon arrangements on site because the bridge adopted a symmetrical erection manner, and a comparison of the counterparts can be performed between the east and west bank cases. Finally, considering a certain safety stock, the longitudinally different patterns of prestressing for the field test with the comparison objects are illustrated in Figure 9(c) and Table 3. The tendons were uniformly arranged along the transverse direction of the cross-section, and all the tensioning manipulations were performed as soon as the concrete reached $85 \%$ strength. Except for the no. 10, 11, 16, and 17 segments in the east bank, which adopted the single-segment tensioning, all segments used the two-segment tensioning.

To precisely validate the prestressing effects in consideration of the spatial effects [32], a spatial lattice grid model through a series of development [33-36] was employed to model the construction step. The method first discretizes a box girder with thin plates and uses the equivalent grids to model the plate. The top, bottom, and web plates are then represented by different orthogonal grillages. The moments of inertia of the longitudinal and transverse beams are determined by the widths of the parallelly divided plate members. The material properties of the bridge are shown in Table 4, and the calculation span, rise, and arch axis coefficient are $242.7 \mathrm{~m}, 40.45 \mathrm{~m}$, and 1.895 , respectively. The main arch ring structure is transversely divided into 15 beams with 4 set as virtual beams at the corner points and longitudinally divided into 37 segments, as shown in Figures 10(a) and 10(b). The in-site procedure is shown in Figure 11, where the initial segment at the arch foot was erected by the scaffolding method and the closure one by hoisting, and the remaining 34 were installed by cantilever casting.

The comparison results are shown in Figures 12(a)12(f). In Figure 12(a), the upper edge tensile stresses of the no. 10 and 11 segments in the east and west banks decreased by approximately $0.6 \sim 0.8 \mathrm{MPa}$ after prestressing, and the stress variation trends of the two tensioning patterns were almost the same but differed in their values because of the different amount of the tendons between the east and west bank cases. In Figures 12(b) and 12(c), the stress variations of the no. 12 and 13 segments in the west bank were similar with that of the no. 10 and 11 segments due to the same prestressing arrangement, but the bottom plate prestressing in the east bank introduced a tensile stress increment of $0.05 \mathrm{MPa}$ in the upper edge, which is too small to impact the corresponding stress distribution. This neither satisfies the stress index requirement nor does it exceed the allowable concrete tensile stress $(2.04 \mathrm{~Pa})$. The compressive stress increment in the east bank at the lower edge is approximately $0.3 \mathrm{MPa}$, whereas in the west bank, the top plate prestressing introduces a tensile stress increment of $0.2 \mathrm{MPa}$ in the lower edge.

In Figures 12(d) and 12(e), the upper edge stress variations of the no. 14 and 15 segments in the west bank are 
TABLE 3: Comparison objects of temporary prestressing between the east and west bank cases.

\begin{tabular}{|c|c|c|c|c|c|c|}
\hline \multirow[t]{2}{*}{ Case } & \multicolumn{2}{|l|}{ Temporary prestressing schemes } & \multirow{2}{*}{$\begin{array}{l}\text { Segment } \\
\text { no. }\end{array}$} & \multicolumn{2}{|c|}{$\begin{array}{l}\text { Stress control } \\
\text { index }(\mathrm{MPa})\end{array}$} & \multirow{2}{*}{$\begin{array}{l}\text { Tensioning stress } \\
(\mathrm{MPa})\end{array}$} \\
\hline & East bank & West bank & & Upper & Lower & \\
\hline 1 & Single-segment tensioning & Two-segment tensioning & 10,11 & 0.5 & 0.5 & 1395 \\
\hline 2 & Bottom plate prestressing & Top plate prestressing & 12,13 & 0.5 & 0.5 & 1395 \\
\hline 3 & Prestressing in both the plates & Top plate prestressing & 14,15 & 0 & 0 & 1395 \\
\hline 4 & $\begin{array}{l}\text { The distances from the upper edge to the prestressing } \\
\text { resultant points are } 15 \mathrm{~cm} \text { and } 10 \mathrm{~cm} \text {, respectively }\end{array}$ & $\begin{array}{l}\text { Arrange along the center } \\
\text { line of the top plate }\end{array}$ & 16,17 & 0 & 0 & 1395 \\
\hline
\end{tabular}

TABle 4: Properties of the materials.

\begin{tabular}{lccc}
\hline Item & Density $\left(\mathrm{kN} / \mathrm{m}^{3}\right)$ & Moment of inertia $\left(10^{3} \mathrm{MPa}\right)$ & Poisson ratio \\
\hline Concrete $(\mathrm{C} 60)$ & 2500 & 36.0 & 0.22 \\
Steel strand & 7800 & 195.0 & 0.30 \\
Steel & 7800 & 200.0 & 0.30 \\
\hline
\end{tabular}

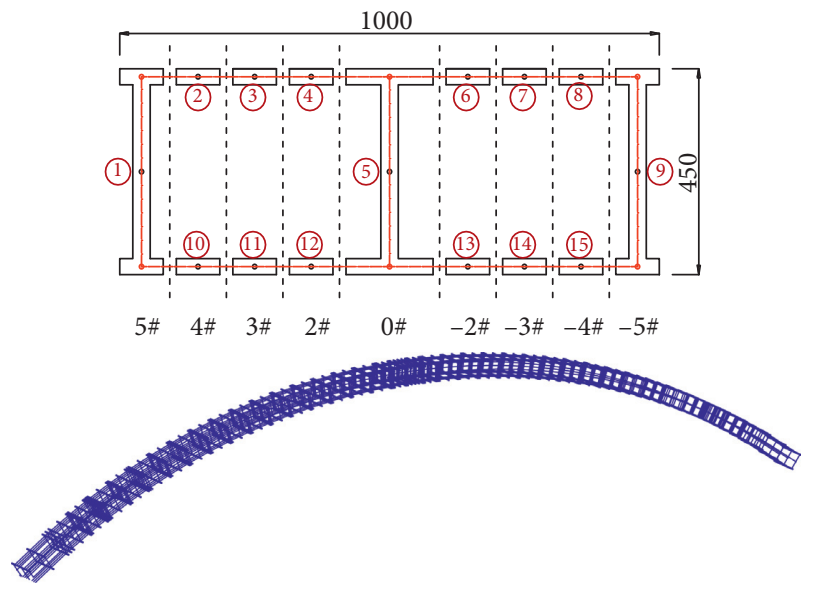

(a)

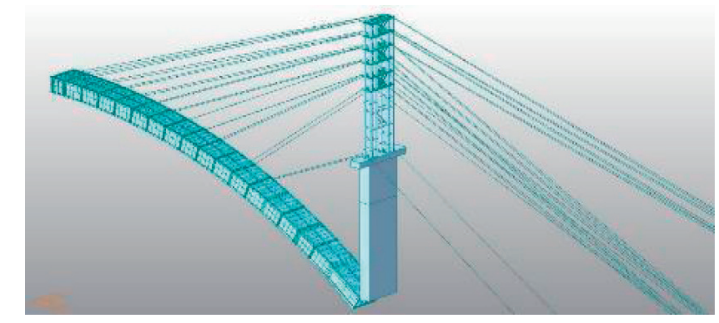

(b)

Figure 10: Spatial grillage modeling of the Shatuo Bridge under construction (unit: $\mathrm{cm}$ ). (a) Cross-sectional division and arch ring model. (b) Spatial grid model of construction step.

similar with that of the no. 10 and 11 segments due to the same prestressing arrangement. However, the lower edge tensile stresses have an increment of $0.2 \mathrm{MPa}$. The case of simultaneous prestressing in the top and bottom plates in the east bank obtained a compressive stress increment of approximately $0.2 \sim 0.8 \mathrm{MPa}$ in the upper and lower edges, but the mutual impacts lowered the declines by approximately $0.05 \mathrm{MPa}$. In Figure 12(f), the upper edge tensile stresses of the no. 16 and 17 segments have a similar decline of approximately $0.6 \sim 0.8 \mathrm{MPa}$, and the decline was more significant in the east bank than in the west bank.

As can be seen, prestressing in the box-type arch ring can remarkably lower the tensile stress level in the corresponding cantilever segment, and it can reduce the erection control difficulties and concrete cracking risks. The singlesegment tensioning has similar integral prestressing effects with the two-segment tensioning, but it is not able to control the stresses of the first segment. The case of simultaneous prestressing in the top and bottom plates can eliminate the cross-sectional tensile stresses with a balanced compressive stress reserve, but if one-side prestressing is employed as a choice for specific convenience of construction, the allowable stress requirement specified by the code $[30,31]$ can at least be satisfied based on reducing the maximum crosssectional tensile stress. Compared with the eccentrical prestressing arrangement for the plate cross-section, the central line prestressing arrangement has a better control effect in minimizing the cross-sectional tensile stresses.

To perform a field test validation, the strain sensors were transversely installed along the upper and lower edges of the critical cross-section to record the longitudinal strain data before and after prestressing. The influences of the prestressed tendons on the maximum tensile stresses of the segments during construction are first analyzed. Here, taking the stress variation at the upper edge of the top plate as an example, the comparative results in the two bank cases are both shown in Figures 12(g) and 12(h). What can be observed is that the tensile stress level was reduced by 


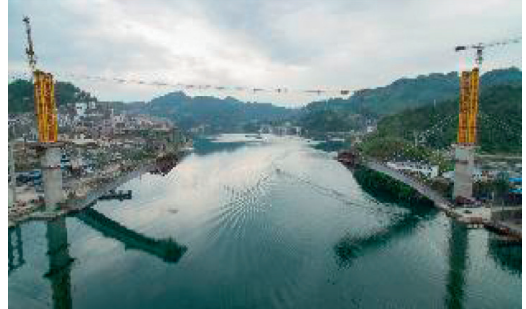

(a)

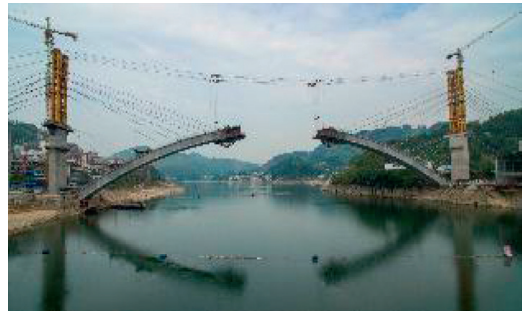

(d)

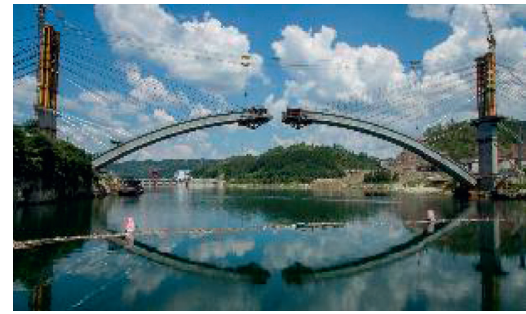

(g)

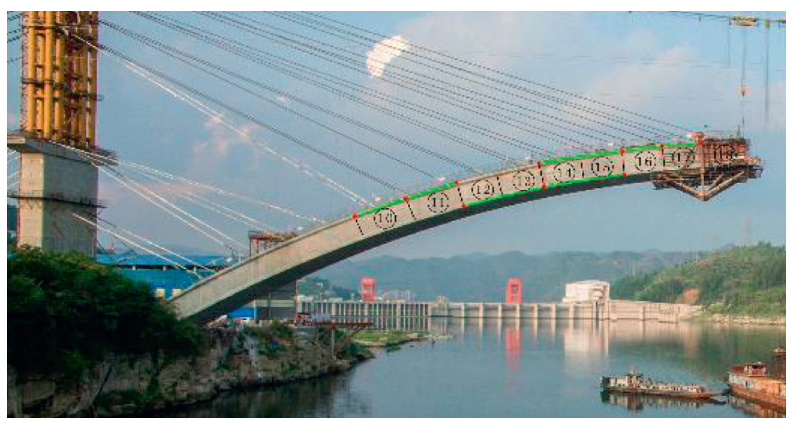

(j)

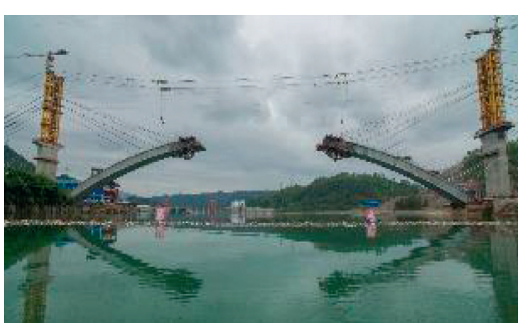

(b)

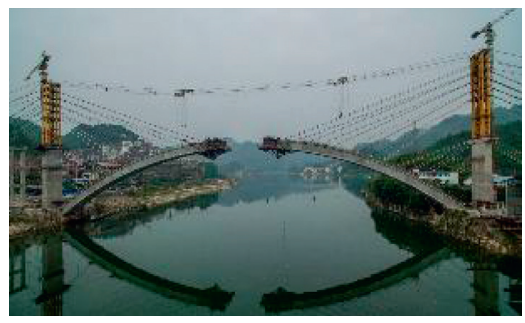

(e)

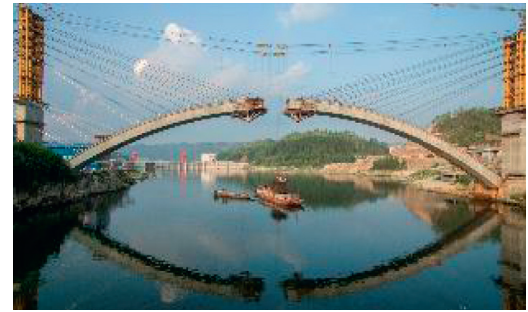

(h)

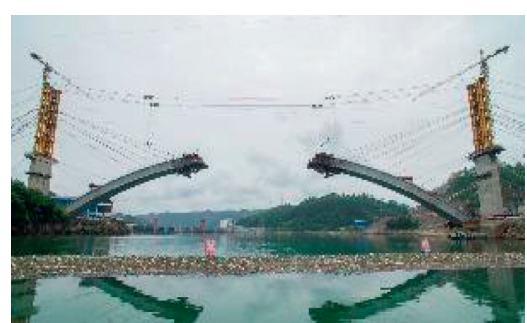

(c)

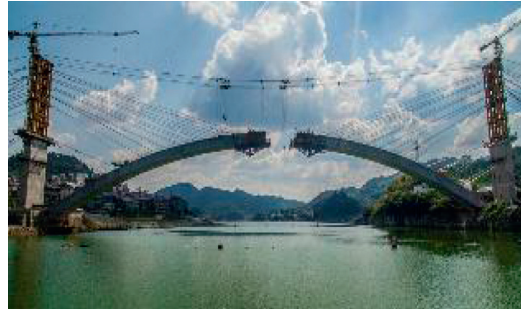

(f)

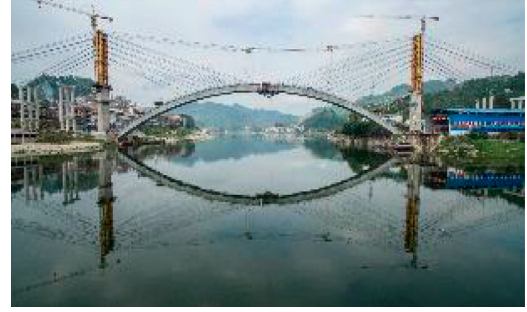

(i)

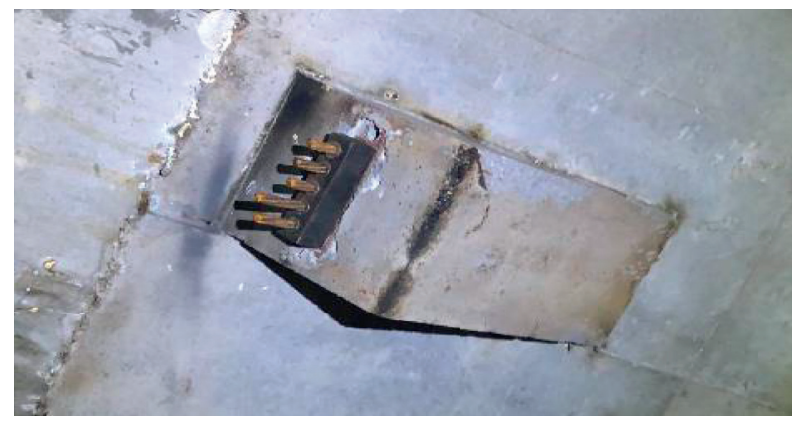

(k)

Figure 11: In-site erection procedure of the main arch ring of the Shatuo Bridge and tendon layout. (a) East no. 10 and west no. 10 . (b) East no. 12 and west no. 13. (c) East no. 13 and west no. 13. (d) East no. 14 and west no. 14. (e) East no. 16 and west no. 16. (f) East no. 17 and west no. 16. (g) East no. 18 and west no. 16. (h) East no. 18 and west no. 17. (i) East no. 18 and west no. 18. (j) Tendon layout in the east coast in site. (k) Prestressed tension end in site.

approximately $0.4 \sim 1.0 \mathrm{MPa}$ in either bank case by using the prestressing arrangements. The theoretical and field test values also have a good agreement in terms of their trends and magnitudes. For the east coast case, since the tension stresses in the upper edge of the no. 10 segment are more obvious, based on the effectiveness of the model, a second tendon scheme of better improving the concrete safety reserve of the no. 10 segment during construction is listed in Table 5 , with its tensile stress reduction $(>2 \mathrm{MPa})$ shown in Figure 13.

With the help of the temporary short prestressed tendons, a one-off stretching design of the buckle cables was easily realized instead of multiple stretching in the conventional manners because the tensile stresses of the arch ring were more reasonably controlled.

\section{Application Discussion}

With the proposed technique upgrades on the design and monitoring-control of the temporary facilities applied in the Shatuo Bridge, the construction efficiency of the main arch ring has been significantly improved and a substantial cost has been saved, with a more precise finished line shape and safer erection environment. It is assumed that the cantilever construction of the main arch ring is performed smoothly disregarding any emergencies, such as unfavorable weather, 


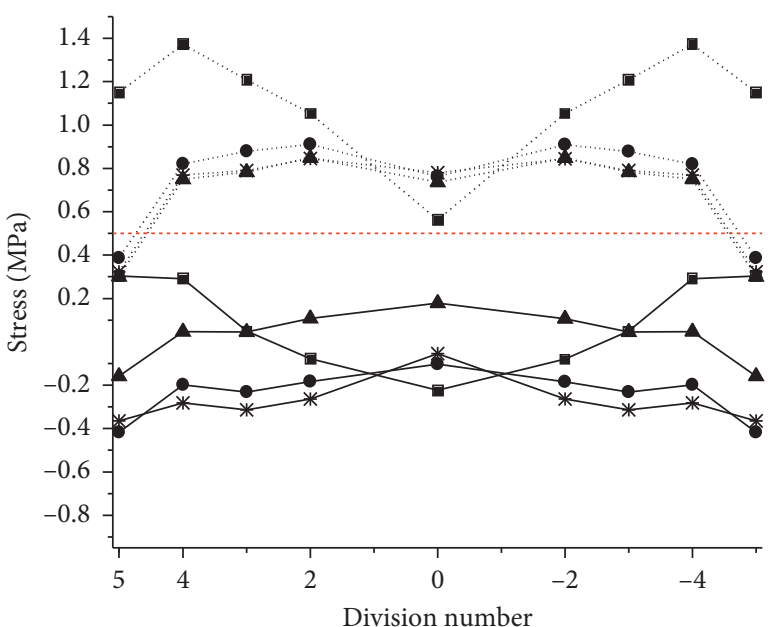

-.... West side 10\# before tensioning

-... West side 11\# before tensioning

$\rightarrow$ West side 10\# after tensioning

$\rightarrow$ West side 11\# after tensioning

(a)

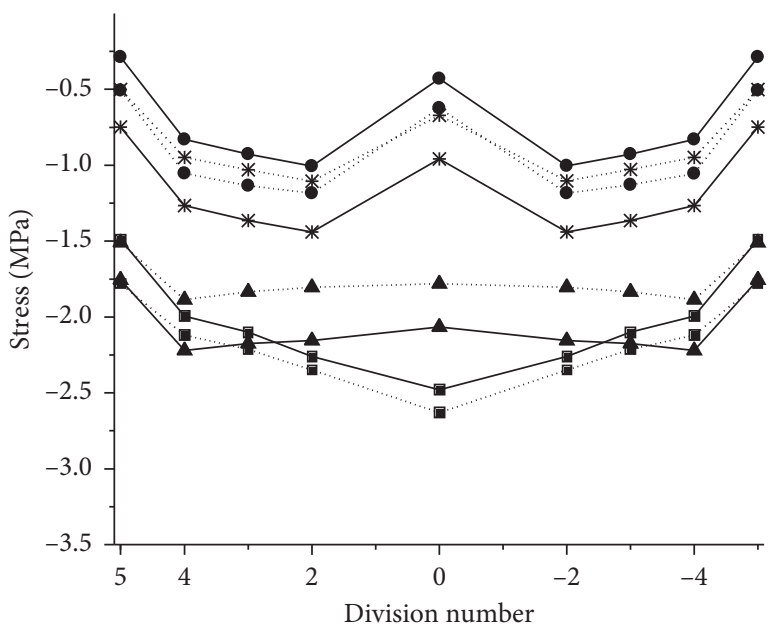

..... West side 12\# before tensioning

-... West side 13\# before tensioning

..... East side 10\# before tensioning

*... East side 11\# before tensioning

ــ East side 10\# after tensioning

* East side 11\# after tensioning

$\rightarrow$ West side 12\# after tensioning

\... East side 12\# before tensioning

...... East side 13\# before tensioning

ــ East side 12\# after tensioning

$\rightarrow$ West side 13\# after tensioning
* East side 13\# after tensioning

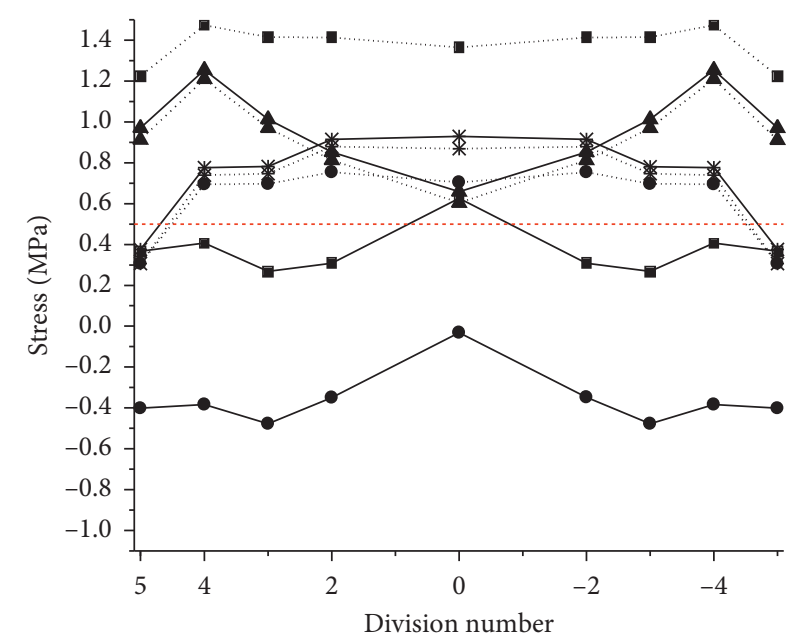

[.... West side 12\# before tensioning

-... West side 13\# before tensioning

... East side 12\# before tensioning

West side 12\# after tensioning

*... East side 13\# before tensioning

- West side 13\# after tensioning

East side 12\# after tensioning

* East side 13\# after tensioning

(b)

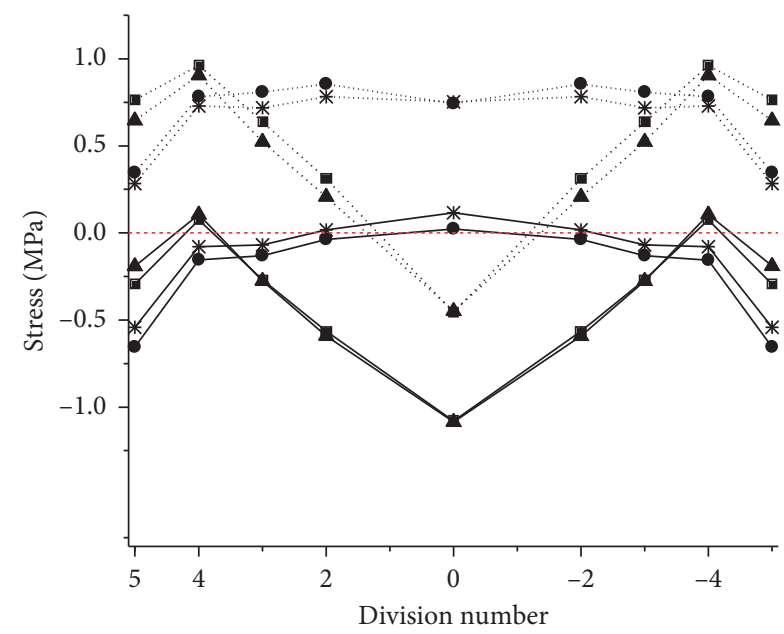

...... West side 14\# before tensioning

•... West side 15\# before tensioning

¿... East side 14\# before tensioning

West side 14\# after tensioning

* East side 15\# before tensioning

ــ East side 14\# after tensioning

$\rightarrow$ West side 15\# after tensioning

* East side 15\# after tensioning

(d)

Figure 12: Continued. 


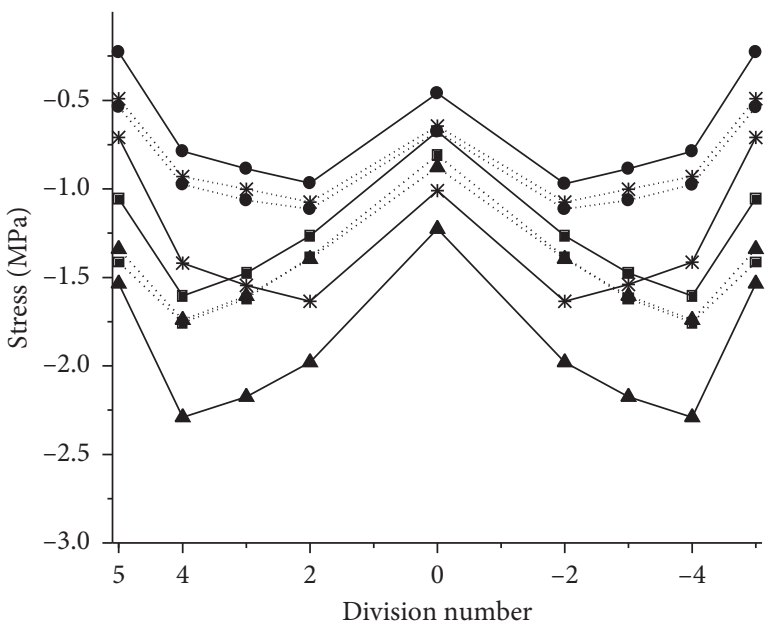

-.... West side 14\# before tensioning

-... West side 15\# before tensioning

$\rightarrow$ West side 14\# after tensioning

$\longrightarrow$ West side 15\# after tensioning

$(\mathrm{e})$

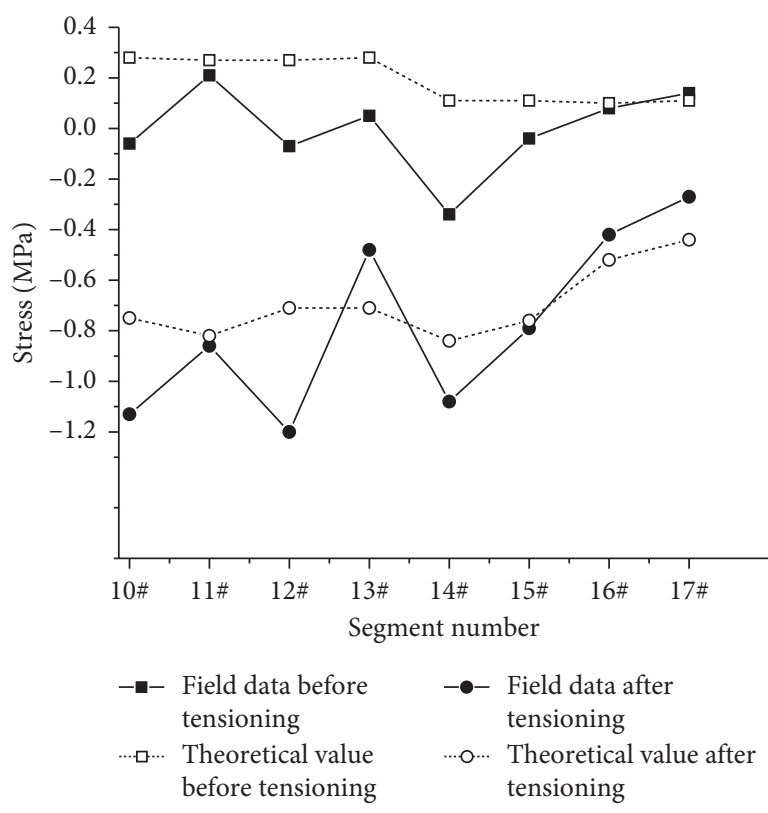

(g)

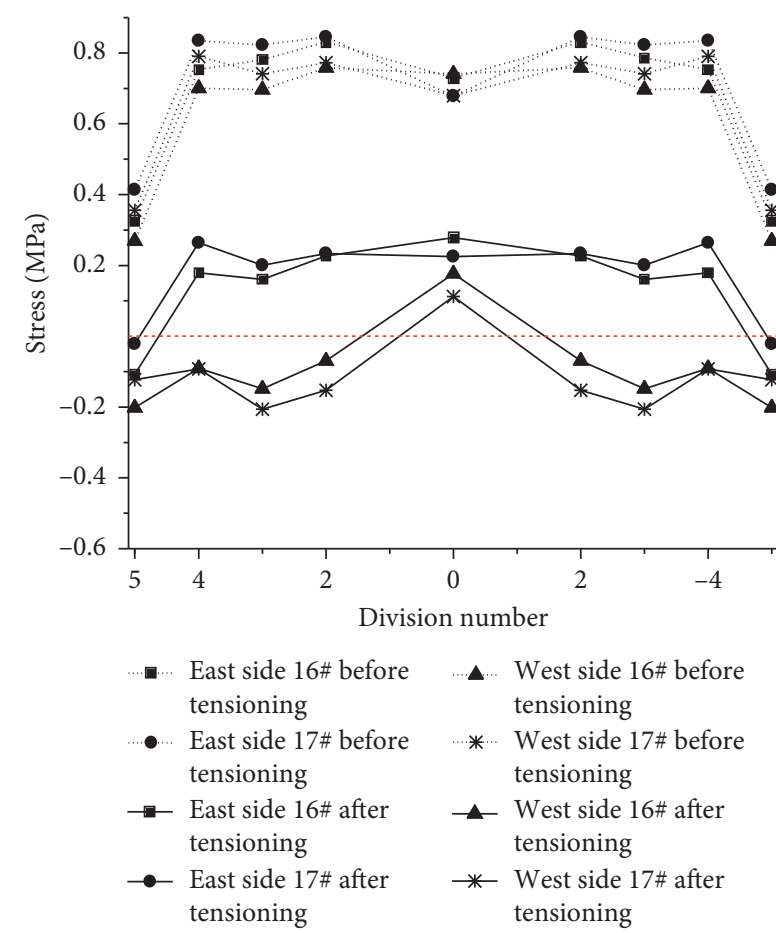

(f)

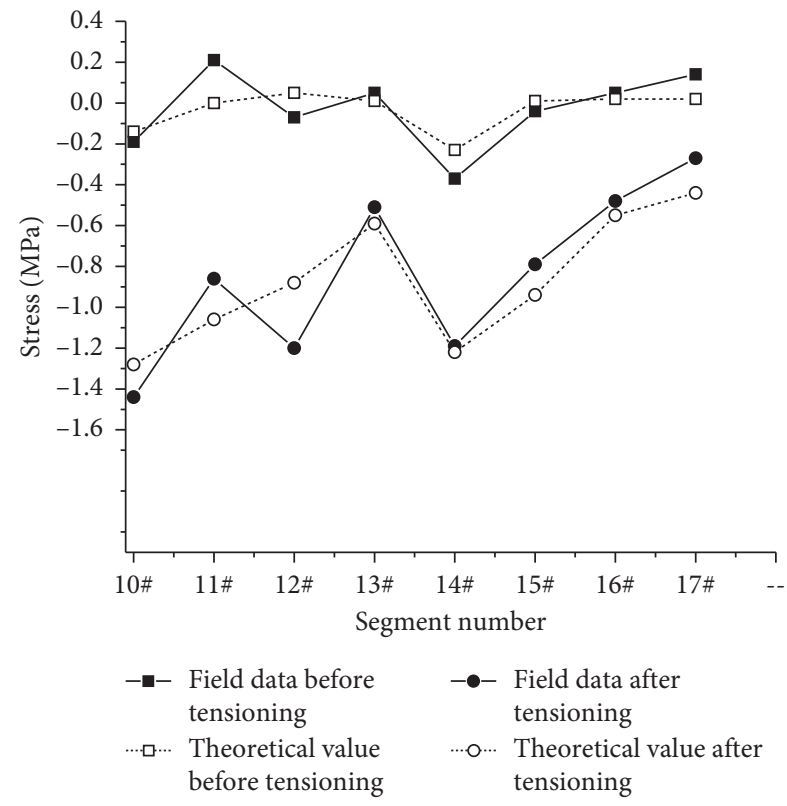

(h)

Figure 12: Comparisons of the prestressing patterns and field test of the upper edge tensile stresses. The abscissas from (a) to (f) denoting the numbering of the divided beam cross-sectional areas can refer to Figure 10(a). (a) Upper edge stress distribution of the end cross sections of the no. 10 and 11 segments (case 1). (b) Upper edge stress distribution of the end cross sections of the no. 12 and 13 segments (case 2). (c) Lower edge stress distribution of the end cross sections of the no. 12 and 13 segments (case 2). (d) Upper edge stress distribution of the end cross sections of the no. 14 and 15 segments (case 3). (e) Lower edge stress distribution of the end cross-sections of the no. 14 and 15 segments (case 3). (f) Upper edge stress distribution of the end cross sections of the no. 16 and 17 segments (case 4). (g) Maximum upper edge tensile stresses (east field data). (h) Maximum upper edge tensile stresses (west field data).

operational errors, and meetings., and the old style erection could reluctantly be performed without consideration of any failure cases. The efficacy of the new technical manners on the temporary facilities can be compared with that of traditional construction manners, in which a one-off stretching design is not easy to realize and the European or Japanese style form traveler does not move as efficiently as the new inverted triangle one, as shown in Table 6. The 
TABLE 5: Temporary prestressing scheme for improving safety reserve of the upper edge of the no. 10 segment.

\begin{tabular}{lcc}
\hline Segment no. & \multicolumn{2}{c}{ West } \\
\hline 9 & 24 & Bottom \\
10 & 30 & 0 \\
11 & 34 & 0 \\
12 & 32 & 0 \\
13 & 30 & 0 \\
14 & 44 & 0 \\
15 & 34 & 16 \\
16 & 26 & 16 \\
17 & 20 & 12 \\
18 & 0 & 10 \\
\hline
\end{tabular}

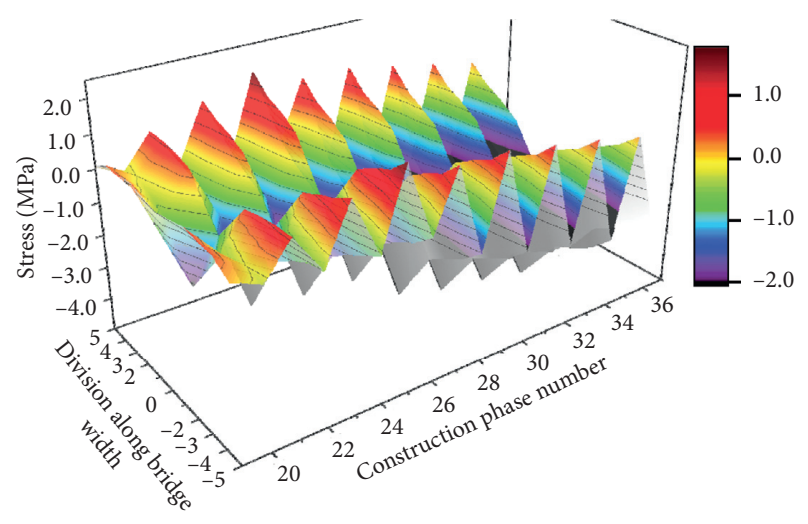

(a)

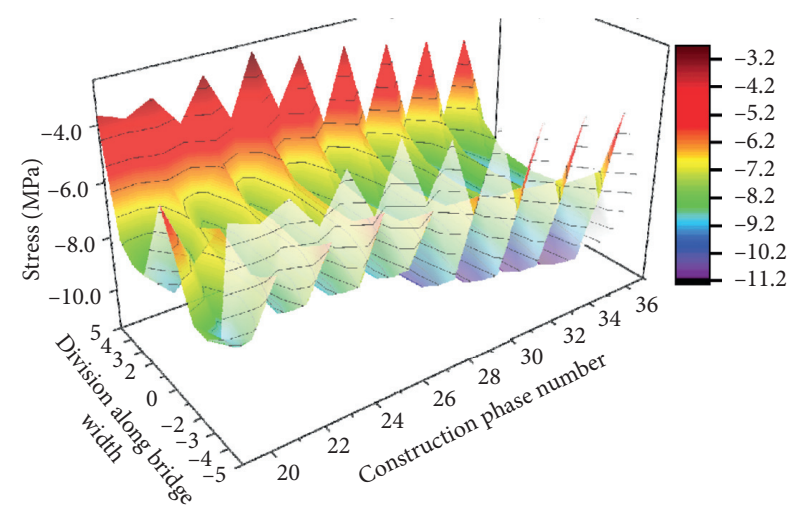

(b)

Figure 13: Effects of the rectified short prestressed tendon scheme for improvement of the safety reserve of the no. 10 segment. (a) No. 10 segment upper edge without prestressing. (b) No. 10 segment upper edge with prestressing.

amount of time saved is obtained by an average data of the two form travelers in constructing one box-type cantilever segment, 5 7 $\mathrm{m}$ in length, based on the past experiences, and the amount of cost saved is mainly calculated in consideration of the everyday running cost of the construction site of the Shatuo Bridge. Then, we can see that the minimum erection time for one cantilever arch segment can be minimized to eight days, which is similar with the erection
TABLE 6: Efficacy promotion of the new techniques applied in the Shatuo Bridge (unit: MPa).

\begin{tabular}{lccccc}
\hline $\begin{array}{l}\text { Cantilever } \\
\text { casting }\end{array}$ & $\begin{array}{c}\text { Traditional } \\
\text { manner } \\
\text { (day) }\end{array}$ & $\begin{array}{c}\text { Stretch } \\
\text { saving } \\
\text { (day) }\end{array}$ & $\begin{array}{c}\text { Traveler } \\
\text { saving } \\
\text { (day) }\end{array}$ & $\begin{array}{c}\text { New } \\
\text { techniques } \\
\text { (day) }\end{array}$ & $\begin{array}{c}\text { Cost } \\
\text { saving } \\
\left(10^{4}\right. \\
\text { RMB) }\end{array}$ \\
\hline $\begin{array}{l}\text { One } \\
\text { segment }\end{array}$ & $10 \sim 12$ & & $0.5 \sim 1$ & $8 \sim 10$ & $4 \sim 7$ \\
$\begin{array}{l}\text { Total } \\
(2 \sim 18 \#)\end{array}$ & $170 \sim 204$ & $8.5 \sim 17$ & $8.5 \sim 17$ & $136 \sim 170$ & $136 \sim 238$ \\
\hline
\end{tabular}

time of casting a box girder segment in a continuous beam bridge. The maximum cost saving is up to 2,380,000 RMB during the cantilever casting phases. In practice, the total construction cost of the main structure of the Shatuo Bridge is approximately $11,000 \mathrm{RMB} / \mathrm{m}^{2}\left(1640 \mathrm{USD} / \mathrm{m}^{2}\right)$, which is economically competitive compared with other schemes over the same span.

Note that the safety control of the buckle-anchor system in the construction process is ensued by the automatic deviation-rectifying control system. Although a practical erection procedure of the main arch ring may possibly be performed without an automatic cable adjustment system and intervention of the rectifying behaviors, the unpredictable large sum of manual manipulations will substantially increase the control difficulties and slow down the economy in a cantilever casting. While this consuming cannot be directly measured, it is extremely important for assuring the construction quality and efficacy by using the techniques. It should also be noted that, although the working flow except for the concrete casting process seems like to be a promisingly automatic one, there are still two limitations, which could risk the construction process. First, it is the first time that we combine a real-time rectifying buckle-anchor system and an automatic tensioning system together, and it is necessary that some professional workers should stay in situ to make sure that each machine or equipment is in a normal state at all times. Second, unpredictable environment facets may have substantial impact on the behaviour of the temporary facilities, and the process should be manually terminated once an extreme weather or ground motion happens. However, in the future, a completely automatic process may be developed by taking all of the manual facets into account.

\section{Conclusion}

With the proposed technical upgrades for the temporary facilities of the concrete box-type arch bridges, the main arch ring of the Shatuo Bridge achieved closure in November 2018, and the line shape and stresses were successfully controlled. The contributions of this case study can be concluded as follows.

(1) An adaptive design of the form traveler was used to eliminate the defects of the traditional designs in the construction of large-span concrete box-type arch bridges in terms of the line shape manufacturing precision, construction efficiency, and structural 
safety. This was performed by upgrading the structural rationalities and motion fluency based on the features of the main arch ring, with a load ratio of 0.29.

(2) The automatic cable adjustment system and the dynamic pylon deviation observation system were designed based on the synchronizing tensioning technology, as well as the ultrasonic and laser measuring technology. These were combined into an integrated control system to form a semiautomatic deviation-rectifying buckle-anchor system to promote the safety and efficiency of the buckle-anchor system. The buckle and anchor cable system can obtain the data of the pylon displacement and the tension forces of the buckles and anchor cables in a real-time manner and perform an active intervention.

(3) Setting well-directed temporary prestressed tendons in the arch ring can effectively reduce the tension stresses of the concrete and the control difficulties of the main arch ring in the construction of large span concrete box-type arch bridges. The manner facilitates a one-off stretching design of the buckle cables that can greatly improve the efficiency of the stretching process.

By using the new technical upgrades of the temporary facilities, the construction efficacy of the Shatuo Bridge was significantly promoted, and the total construction cost of the main bridge was approximately $11,000 \mathrm{RMB} / \mathrm{m}^{2}$. Compared with other bridge schemes over the same span, the economic indicators of the bridge are competitive, and the future maintenance cost of the bridge is also lower than that of other types of bridges.

\section{Data Availability}

All field test data and structural design data used during the study are available from GuiZhou Road \& Bridge Group Co., Ltd. by request ((1) stress and displacement field test data; (2) design drawings; and (3) site photos). All FE models and analytical data used during the study are available from the corresponding author by request ((1) FE model of the structures; (2) structural analytical data.)

\section{Conflicts of Interest}

The authors declare no conflicts of interest.

\section{Acknowledgments}

This work was supported by the Fundamental Research Funds for the Central Universities (HUST: 2018KFYYXJJ003). It is also supported by the National Natural Science Foundation of China (Grant nos. 51408249 and 51708436).

\section{References}

[1] F. T. K. Au, J. J. Wang, and G. D. Liu, "Construction control of reinforced concrete arch bridges," Journal of Bridge Engineering, vol. 8, no. 1, pp. 39-45, 2003.
[2] K. Chen and J. Y. Song, "Survey and analysis of exiting reinforced concrete ribbed arch bridges," Advanced Materials Research, vol. 255-260, pp. 1187-1191, 2011.

[3] J. Salonga and P. Gauvreau, "Comparative study of the proportions, form, and efficiency of concrete arch bridges," Journal of Bridge Engineering, vol. 19, no. 3, Article ID 04013010, 2014.

[4] W. X. Xie, T. S. Zhao, J. J. Tang, and Y. Zhang, "Arch first and beam later: arch-rib integral installation construction technology for large-span tied-arch bridge," Journal of Construction Engineering and Management, vol. 143, no. 8, Article ID 04017059, 2017.

[5] J. Zhang and T. E. El-Diraby, "Constructability analysis of the bridge superstructure rotation construction method in China," Journal of Construction Engineering and Management, vol. 132, no. 4, pp. 353-362, 2006.

[6] N. Pnevmatikos and V. Sentzas, "Preliminary estimation of response of curved bridges subjected to earthquake loading," Journal of Civil Engineering and Architecture, vol. 6, pp. 1530-1535, 2010.

[7] I. Mohseni, H. A. Lashkariani, J. Kang, and T. H. K. Kang, "Dynamic response evaluation of long-span reinforced arch bridges subjected to near- and far-field ground motions," Applied Sciences, vol. 8, no. 8, p. 1243, 2018.

[8] ASCEC (The ASCE Committee on Construction Equipment and Techniques), "Concrete bridge design and construction in the United Kingdom," Journal of Construction Engineering and Management, vol. 115, no. 4, pp. 618-635, 1989.

[9] N. J. Gimsing, "Evolution in span length of cable-stayed bridges," in Proceedings of the International Conference on Bridge Engineering: Challenges in the 21st Century: Kowloon Shangri-La Hotel, Hong Kong, The Hong Kong Institution of Engineers, Hong Kong, China, November 2006.

[10] J.-H. Won, K. I.-I. Cho, J.-H. Yoon, and S.-H. Kim, "Innovative key-segment closing method using thermal prestressing technique for partially earth-anchored cable-stayed bridges," Advances in Structural Engineering, vol. 11, no. 5, pp. 549-564, 2008.

[11] J. Yang, S. X. Zhou, and H. J. Han, Cantilever Casting Concrete Arch Bridge Design and Construction Technology, China Communications Press, Beijing, China, 2015.

[12] R. H. Wang, Z. J. Zhang, C. G. Dong, and Y. H. Huang, "Fast algorithm and its application in construction monitoring of parallel strand cables," Journal of Bridge Engineering, vol. 20, no. 9, Article ID 04014100, 2015.

[13] P. Heinz and M. Gerard, "Mounting tension: single strand tensioning," Concrete Engineering International, vol. 6, no. 4, pp. 50-53, 2000.

[14] W.-X. Ren, "Ultimate behavior of long-span cable-stayed bridges," Journal of Bridge Engineering, vol. 4, no. 1, pp. 30-37, 1999.

[15] A. S. Vlahinos, J. C. Ermopoulos, and Y.-C. Wang, "Buckling analysis of steel arch bridges," Journal of Constructional Steel Research, vol. 26, no. 1, pp. 59-71, 1993.

[16] Y.-C. Wang, "Number of cable effects on buckling analysis of cable-stayed bridges," Journal of Bridge Engineering, vol. 4, no. 4, pp. 242-248, 1999.

[17] B. J. Chen, Y. S. Xu, and B. C. Chen, "Investigation and analysis of Japanese reinforced concrete arch bridges," Journal of China \& Foreign Highway, vol. 25, no. 4, pp. 96-101, 2005.

[18] Z. H. Lou, "Introduction of the rance river arch bridge in France," Journal of China \& Foreign Highway, vol. 3, pp. 22-23, 1991. 
[19] P. H. Wang, T. Y. Tang, and H. N. Zheng, "Analysis of cable stayed bridges during construction by cantilever methods," Computers \& Structures, vol. 82, no. 4-5, pp. 329-346, 2004.

[20] R. Sirolli and S. Capitanio, "The Bloukrans prestressed concrete arch bridge, the biggest on the African continent," L'Industria Italiana del Cemento, vol. 56, no. 3, pp. 284-309, 1986.

[21] M. F. Granata, P. Margiotta, A. Recupero, and M. Arici, "Partial elastic scheme method in cantilever construction of concrete arch bridges," Journal of Bridge Engineering, vol. 18, no. 7, pp. 663-672, 2013.

[22] Y. Cao, J. Yim, Y. Zhao, and M. L. Wang, "Temperature effects on cable stayed bridge using health monitoring system: a case study," Structural Health Monitoring, vol. 10, pp. 523-537, 2010.

[23] Z. Sun, Z. Zou, and Y. Zhang, "Utilization of structural health monitoring in long-span bridges: case studies," Structural Control and Health Monitoring, vol. 24, Article ID e1979, 2017.

[24] K. Erazo, D. Sen, S. Nagarajaiah, and L. Sun, "Vibration-based structural health monitoring under changing environmental conditions using Kalman filtering," Mechanical Systems and Signal Processing, vol. 117, pp. 1-15, 2019.

[25] H. W. Zhao, Y. L. Ding, S. Nagarajaiah, and A. Q. Li, "Behavior analysis and early warning of girder deflections of a steel-truss arch railway bridge under the effects of temperature and trains: case study," Journal of Bridge Engineering, vol. 24, Article ID 05018013, 2019.

[26] H. Sekiya, O. Maruyama, and C. Miki, "Visualization system for bridge deformations under live load based on multipoint simultaneous measurements of displacement and rotational response using MEMS sensors," Engineering Structures, vol. 146, pp. 43-53, 2017.

[27] J. A. Lozano-Galant, I. Payá-Zaforteza, D. Xu, and J. Turmo, "Analysis of the construction process of cable-stayed bridges built on temporary supports," Engineering Structures, vol. 40, pp. 95-106, 2012.

[28] J. A. Lozano-Galant and J. Turmo, "An algorithm for simulation of concrete cable-stayed bridges built on temporary supports and considering time dependent effects," Engineering Structures, vol. 79, pp. 341-353, 2014.

[29] Y. Sun, H.-P. Zhu, and D. Xu, "A specific rod model based efficient analysis and design of hanger installation for selfanchored suspension bridges with 3D curved cables," Engineering Structures, vol. 110, pp. 184-208, 2016.

[30] MOT (Ministry of Transportation), Technical Specification for Construction of Highway Bridge and Culverts, China Communications Press, Beijing, China, 2011, in Chinese.

[31] MOC\&GAO (Ministry of Construction \& General Administration of Quality Supervision, Inspection and Quarantine), Code for Design of Steel Structures. GB 50017-2003, China Communications Press, Beijing, China, 2003, in Chinese.

[32] C. Liu and D. Xu, "Space frame latice model for stress analysis of bridge," The Baltic Journal of Road and Bridge Engineering, vol. 5, no. 2, pp. 98-103, 2010.

[33] WISEPLUS, "Shanghai, shanghai WISEPLUS software, inc.," 2009, http://www.wiseplus.cn/.

[34] Y. Sun, D. Xu, B. Chen, F.-Y. Xu, and H.-P. Zhu, "Threedimensional reinforcement design method and program realization for prestressed concrete box-girder bridges based on a specific spatial lattice grid model," Engineering Structures, vol. 175, pp. 822-846, 2018.
[35] C. Liu, D. Xu, L. Li, and W. Cheng, "Behavior of concrete segmental box girder bridges with open webs," Journal of Bridge Engineering, vol. 20, no. 8, Article ID B4015003, 2015.

[36] D. Xu, Y. Ni, and Y. Zhao, "Analysis of corrugated steel web beam bridges using spatial grid modelling," Steel and Composite Structures, vol. 18, no. 4, pp. 853-871, 2015. 